\title{
Enterovirus replication and dissemination are differentially controlled by type I and III interferons in the GI tract
}

\author{
Alexandra I. Wells ${ }^{1}$, Kalena A. Grimes ${ }^{1}$, and Carolyn B. Coyne ${ }^{1,2^{*}}$ \\ ${ }^{1}$ Department of Molecular Genetics and Microbiology, ${ }^{2}$ Duke Human Vaccine Institute, Duke \\ University School of Medicine, Durham, NC, USA
}

Running title: Enterovirus infection of the intestine in vivo

${ }^{*}$ Address correspondence:

Carolyn Coyne, PhD

3130 Medical Sciences Research Building III

3 Genome Court

48 Durham, NC 27710

49 USA

50 carolyn.coyne@duke.edu 


\section{Abstract}

52 Enteroviruses are amongst the most common viral infectious agents of humans and cause a 53 broad spectrum of mild-to-severe illness. Enteroviruses are primarily transmitted by the fecal-oral

54 route, but the events associated with their intestinal replication in vivo are poorly defined. Here, 55 we developed a neonatal mouse model of enterovirus infection by the enteral route using 56 echovirus 5 and used this model to define the differential roles of type I and III interferons (IFNs)

57 in enterovirus replication in the intestinal epithelium and subsequent dissemination to secondary

58 tissues. We show that human FcRn, the primary receptor for echoviruses, is essential for intestinal 59 infection by the enteral route and that type I IFNs control dissemination to secondary sites, 60 including the liver. In contrast, type III IFNs limit enterovirus infection in the intestinal epithelium 61 and mice lacking this pathway exhibit persistent epithelial replication. Finally, we show that 62 echovirus infection in the small intestine is cell-type specific and occurs exclusively in enterocytes.

63 These studies define the type-specific roles of IFNs in enterovirus infection of the GI tract and the 64 cellular tropism of echovirus intestinal replication.

\section{Introduction}

67 Enteroviruses are small $(\sim 30 \mathrm{~nm})$ single stranded RNA viruses that are comprised of 68 coxsackieviruses (CVA and CVB), rhinoviruses, poliovirus (PV), enteroviruses 71 and D68 (e.g., 69 EV-71, EV-D68), and echoviruses (which includes $\sim 30$ serotypes). Echoviruses can cause 15$7030 \%$ of nosocomial infections is Neonatal Intensive Care Units (NICUs) and often result in aseptic

71 meningitis and liver failure, which can be fatal ${ }^{1-4}$. The National Enterovirus Surveillance System

72 (NESS) indicates that between the years of 2014-2016 echoviruses were amongst the most 73 commonly circulating enteroviruses in the U.S. ${ }^{5}$. Globally, outbreaks of other echoviruses

74 including echovirus 5 (E5) have been associated with a range of clinical outcomes, with most 75 severe disease occurring in infants and children $^{6-8}$. 
Enteroviruses are primarily transmitted through the fecal-oral route and initiate host entry

77 via the epithelial lining of the GI tract. We have previously shown that echoviruses robustly infect

78 human stem cell-derived intestinal enteroids and exhibit a cell-type specificity of infection, with

79 preferential infection in enterocytes and enteroendocrine cells ${ }^{9,10}$. Additionally, echovirus

80 infections cause damage to barrier function in enteroid-derived intestinal epithelial monolayer

81 cultures $^{10}$, suggesting that virus-mediated epithelial damage could contribute to dissemination

82 from the intestine. The impact of host innate immune signaling on enteroviral infections in the

83 intestinal epithelium is largely unknown. Previous studies in mouse models using PV and EV71

84 have shown that ablation of type I interferon (IFN) signaling by deletion of the IFN $\alpha / \beta$ receptor

85 (IFNAR) is required for infection by the oral route ${ }^{11-13}$, suggesting that these IFNs play a central

86 role in the protection of the GI tract from enterovirus infection. Whether this enhancement was

87 the result of increased infection in the intestinal epithelium directly and/or resulted from alterations

88 in infection of non-epithelial cell types remains unclear. Other studies using CVB show that

89 infection by the enteral route remains inefficient in IFNAR ${ }^{-/-}$animals, suggesting that these IFNs

90 are not involved in intestinal innate immune responses ${ }^{14}$. Consistent with this, type III IFNs, which

91 are comprised of IFN- $\lambda$ s 1-3 in humans, are preferentially induced in enterovirus-infected human

92 enteroids ${ }^{9,10}$. For other enteric viruses, such as reoviruses, rotaviruses, and noroviruses, type III

93 IFNs specifically control viral replication in the intestinal epithelium in vivo, with type I IFNs

94 impacting the lamina propria ${ }^{11,15-18}$. Thus, the roles of type I and III IFNs in the control of

95 enteroviral infections in vivo remain unclear.

96 We and others previously identified the human neonatal Fc receptor (hFcRn) as a primary

97 receptor for echoviruses ${ }^{19,20}$. In contrast, mouse FcRn does not function as an echovirus receptor

98 and does not support replication in vivo ${ }^{19,21}$. FcRn is expressed at the apical membrane of

99 polarized enterocytes, where it binds to IgG and albumin, is internalized by endocytosis, and

100 delivers its cargo to early and late endosomes, with the eventual release of IgG and albumin into

101 the interstitium ${ }^{22}$. However, expression of $\mathrm{hFcRn}$ alone is not sufficient for echovirus infection in 
adult or neonatal mice and ablation of IFNAR in hFcRn-expressing mice is required for infection following intraperitoneal (IP) inoculation ${ }^{21}$. However, the roles of $\mathrm{hFcRn}$ and IFN signaling following inoculation via the enteral route was not explored.

Here, we established in vitro and in vivo models to define the impact of hFcRn expression and type I and III IFN signaling in echovirus infections in the GI tract. To do this, we generated

107 mice expressing hFcRn that are deficient in the type III IFN receptor (IFNLR) and compared their 108 susceptibility to enteral echovirus infection to hFcRn-expressing mice lacking IFNAR expression, 109 or immunocompetent animals expressing $\mathrm{hFcRn}$ alone. Whereas expression of $\mathrm{hFcRn}$ was 110 necessary and sufficient to support echovirus replication in primary murine stem cell-derived 111 enteroids, it was not sufficient for infection of immunocompetent mice following oral gavage. We 112 show that hFcRn-expressing mice deficient in IFNLR expression are unable to control echovirus 113 infection in the $\mathrm{Gl}$ tract and exhibit persistent replication in the intestinal epithelium, which 114 occurred exclusively in enterocytes. However, these animals did not exhibit any morbidity or 115 mortality from infection and there was no dissemination to secondary tissues. In contrast, there 116 was robust dissemination in hFcRn-expressing mice deficient in IFNAR expression, which 117 resulted in significant morbidity and mortality. However, we did not observe active replication in 118 the intestinal epithelium of these animals. These findings define the differential roles of type I and 119 III IFNs in the control of echovirus replication in the GI tract and in subsequent dissemination.

\section{$121 \quad$ Results}

\section{Human FcRn is required for echovirus infection of murine-derived enteroids}

123 To define the role of hFcRn in infections of the murine intestine, we generated neonatal enteroids

124 from C57/BL6 (wild-type, WT) mice and mice expressing hFcRn (hFcRn $\left.{ }^{T g 32}\right) . \mathrm{hFcRn}^{\mathrm{Tg} 32}$ mice are 125 deficient in expression of mouse FcRn and express human FcRn under the control of the native 126 human promotor $^{23}$. Stem cell-derived enteroids differentiated to form three-dimensional structures 127 containing cells present in the epithelium in vivo, including enterocytes and mucin-secreting goblet 
cells (Figure 1A). Consistent with what has been described for murine fibroblasts derived from WT mice ${ }^{19}$, enteroids derived from WT mice were resistant to E5 infection (Figure 1B). In contrast, enteroids derived from $\mathrm{hFcRn}{ }^{\mathrm{Tg} 32}$ mice were highly permissive to $\mathrm{E} 5$ infection, which peaked at 24 hours post inoculation (hpi) (Figure 1B). To define the host response of E5-infected enteroids, we performed bulk RNASeq followed by differential expression analysis. Similar to previous results in human enteroids ${ }^{9}$, murine-derived enteroids induced the selective expression of

134 transcripts associated with the type III IFNs IFN $\lambda-2$ and IFN $\lambda-3$ (mice do not express IFN- $\lambda 1$ )

135 (Figure 1C). Differential expression analysis revealed the induction of 48 transcripts in E5136 infected $\mathrm{hFcRn}{ }^{\mathrm{Tg} 32}$ enteroids, 42 of which are classified as interferon stimulated genes (ISGs)

137 (Figure 1D), supporting a prominent role of IFN signaling in the intestinal innate immune response 138 to echovirus infections.

The selective induction of type III IFNs in murine-derived enteroids suggests that these

140 IFNs are key mediators in the control of echovirus infections in the intestinal epithelium. To test 141 this, we derived enteroids from small intestine tissue of mice expressing hFcRn that are deficient 142 in IFNAR expression $\left(\mathrm{hFcRn}{ }^{T g 32}-\mathrm{IFNAR}^{-/}\right)^{21}$. To perform parallel studies in enteroids deficient in 143 type III IFN signaling, we crossed $\mathrm{hFcRn}{ }^{T g 32}$ mice to mice deficient in IFNLR expression

$144\left(\mathrm{hFCRn}^{T g 32}\right.$ IFNLR $\left.^{-/}\right)$. Enteroids were generated from the small intestines of immunocompetent $145 \mathrm{hFCRn}{ }^{\top \mathrm{g} 32}, \mathrm{hFCRn}^{\top \mathrm{g} 32}{ }_{-} \mathrm{IFNAR}^{-/-}$, and $\mathrm{hFCRn}^{\top \mathrm{g} 32}{ }_{-} \mathrm{IFNLR}^{-/-}$mice and the levels of E5 replication 146 compared between these genotypes. We did not detect any significant differences in E5 147 replication between $\mathrm{hFcRn-expressing} \mathrm{immunocompetent} \mathrm{enteroids} \mathrm{and} \mathrm{those} \mathrm{deficient} \mathrm{in} \mathrm{either}$ 148 IFNAR or IFNLR expression (Figure 1E). These data show that in ex vivo murine-derived enteroid 149 models, hFcRn expression is necessary and sufficient for echovirus infection of the intestinal 150 epithelium. 
As described above, ex vivo enteroid models suggested that echovirus infection of murine-derived intestinal cells depended on expression of hFcRn and were not controlled by either type I or III IFNs. However, enteroids may not fully recapitulate the events associated with infection in vivo. To address this, we used six genotypes of mice, including the humanized FcRn models described

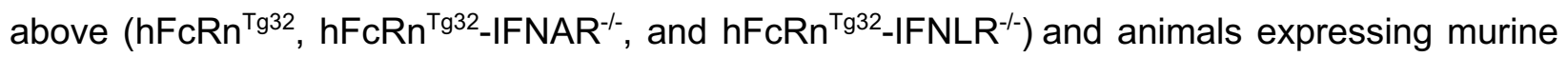
FcRn that were immunocompetent (C57/BL6, WT) or deficient in type I or III IFN signaling (IFNAR'

I- or IFNLR ${ }^{-/-}$, respectively) (Figure 2A). Neonatal (7-day old) mice were orally inoculated with $10^{6}$ PFU of E5 and monitored daily for 7 days for signs of illness (e.g., inactivity, discoloration, lack of nursing, lack of parental care, and death). We observed death in approximately $50 \%$ of $\mathrm{hFcRn}{ }^{\operatorname{Tg} 32}$ IFNAR $^{-/}$animals by 3 days post-inoculation (dpi) and almost $100 \%$ lethality by 7 dpi (Figure 2B). In contrast, there were no clinical symptoms of illness in any other genotype and all animals survived until 7dpi (Figure 2B). There were no significant differences in mortality between male and female hFcRn ${ }^{\top 9} 32$-IFNAR ${ }^{-/-}$mice (Supplemental Figure 1A). intestine, and stool. Infected $\mathrm{hFcRn}{ }^{\mathrm{Tg} 32}$-IFNAR ${ }^{-/-}$animals contained high levels of virus in all tissues collected, with half or more of animals having high viral loads in stomach (7 of 14 mice), duodenum (8 of 14 mice), jejunum (8 of 14 mice), ileum (7 of 14 mice), and large intestine (7 of 14 mice) (Figure 2C-H). In contrast, there was no detectable virus in any tissues isolated from

172 mice not expressing hFcRn, including WT (0 of 10 mice), IFNAR ${ }^{-/-}(0$ of 11 mice $)$, and IFNLR ${ }^{-/-}(0$

173 of 17 mice) (Figure 2 C-H). There were low levels of virus detected in select tissues from 174 immunocompetent $\mathrm{hFcRn}{ }^{\mathrm{Tg} 32}$ animals, which included duodenum ( 3 of 8 mice), jejunum (2 of 8 175 mice), ileum (1 of 8 mice), and large intestine (3 of 8 mice). No virus was recovered from the 176 stomachs of $\mathrm{hFcRn}{ }^{\mathrm{Tg} 32}$ mice (0 of 8 mice). Similarly, low to mid-level titers were observed in $177 \mathrm{hFcRn}{ }^{\top \mathrm{g} 32}$-IFNLR ${ }^{-/-}$mice, with virus recovered from stomach (3 of 15 mice), duodenum (4 of 15 178 mice), jejunum (3 of 15 mice), ileum (3 of 15 mice), and large intestine (4 of 15 mice). Stool 
collected from all genotypes except for WT contained high levels of virus in stool, which may reflect remaining inoculum. There were no significant differences in titers between male and

181 female $\mathrm{hFCRn}^{\mathrm{Tg} 32}$ IFNAR $^{-/-}$mice, although male mice did have overall higher titers in various

182 regions of the small intestine (Supplemental Figure 1B). These data show that $h F c R n$ is 183 necessary, but not sufficient, for echovirus infection of the intestine in vivo and that type I and III 184 IFNs differentially control replication and pathogenesis.

\section{Type I IFNs are the primary drivers of dissemination outside of the GI tract}

187 Given the high degree of mortality in orally inoculated $\mathrm{hFcRn}{ }^{T g 32}$-IFNAR ${ }^{-/-}$mice, we next assessed

188 the levels of infection at key secondary sites of infection at 3dpi, including the liver, pancreas, and 189 brain, which are all targeted by echoviruses in humans. hFcRn ${ }^{T g 32}$-IFNAR ${ }^{-/-}$mice had higher levels 190 of circulating virus (6 of 13 mice), which was not detected in any other genotype (Figure 3A). 191 Consistent with this, we did not detect any virus in the livers, pancreases, or brains of WT, $192 \mathrm{hFCRn}^{\top \mathrm{g} 32}, \mathrm{IFNAR}^{-/-}$, IFNLR ${ }^{-/-}$, or $\mathrm{hFCRn}^{T \mathrm{~g} 32}-\mathrm{IFNLR}^{-/-}$animals (Figure 3B-D). In contrast, $193 \mathrm{hFcRn}{ }^{\top \mathrm{g} 32}$-IFNAR ${ }^{-/-}$mice contained very high titers in liver (7 of 14 mice) and pancreas (7 of 14 194 mice) and lower titers in brain (5 of 14 mice) (Figure 3B-D). There were no significant differences 195 in titers between male and female mice, although male mice did have overall higher titers in the 196 liver (Supplemental Figure 1B). These data are consistent with our previous work data showing 197 that $\mathrm{hFCRn}{ }^{T g 32}$-IFNAR ${ }^{-/-}$pups or adult mice inoculated by the IP route have high levels of echovirus 198 infections in the liver and pancreas ${ }^{21}$.

Next, we performed Luminex multiplex assays to determine the levels of twenty-five 200 circulating cytokines in the blood of E5-infected animals. Consistent with their high levels of 201 dissemination, we found that $\mathrm{hFCRn}^{\mathrm{Tg} 32}$ IFNAR $^{-/-}$mice induced pronounced antiviral and pro202 inflammatory signaling in response to E5 infection, which included high levels of circulating type 203 I IFNs (IFN- $\alpha$ and IFN- $\beta$ ), G-CSF, and IL-6 (Supplemental Figure 2A-D). No other genotypes 204 contained any significant increases in circulating cytokines (Supplemental Figure 2A-D). These 
data are similar to our previous work where IP inoculated $\mathrm{hFcRn}{ }^{\top \mathrm{g} 32}$ IFNAR $^{-/-}$animals had high levels of circulating type I IFNs ${ }^{21}$.

Because we observed significant dissemination of E5 to the livers of orally inoculated $\mathrm{hFCRn}^{\text {Tg32 }}{ }_{\text {IFNAR }}^{-/-}$mice, we next determined if the cellular tropism of echoviruses is the same

209 between the IP and oral routes of inoculation. To do this, we performed hybridization chain

210 reaction $(\mathrm{HCR})$, which allows for multiplexed fluorescent quantitative RNA detection with

211 enhanced sensitivity over conventional hybridization approaches ${ }^{24,25}$. Our previous work using

212 this method showed that echoviruses exclusively target hepatocytes following IP inoculation ${ }^{21}$.

213 We designed probes specific for the E5 genome and used probes to the hepatocyte marker

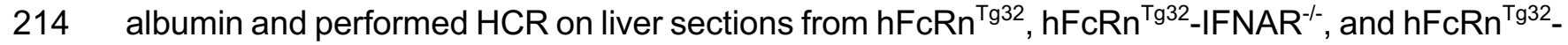

215 IFNLR $^{-1}$ mice orally inoculated with E5 at 3dpi. E5 vRNA positive cells exclusively colocalized with 216 albumin, identifying hepatocytes as the main cellular target of infection in the liver following 217 dissemination from the GI tract (Figure 3E). Collectively, these data show that type I IFNs are the 218 primary drivers of echovirus dissemination from the GI tract to secondary sites including the liver 219 and pancreas.

\section{Type III IFNs limit persistent echovirus infection in the GI epithelium}

222 Because we observed low levels of E5 replication in Gl-derived tissues at 3 dpi, we next compared

223 viral titers from tissues isolated at $7 \mathrm{dpi}$ to determine if there were differences in persistence 224 compared to $\mathrm{hFcRn}{ }^{T g 32}$-IFNAR ${ }^{-/-}$mice. As $\mathrm{hFcRn}^{\mathrm{Tg} 32}$-IFNAR ${ }^{-/-}$mice died from disease before 7dpi, 225 they were excluded from these studies. At $7 \mathrm{dpi}, \mathrm{hFcRn}{ }^{T g} 32-\mathrm{IFNLR}^{-/-}$mice were the only genotype 226 with consistently detectable virus in tissues associated with the GI tract. Whereas select animals 227 had detectable virus in the stomach ( 1 of $7 \mathrm{hFcRn}{ }^{T g} 32$ mice and 2 of $14 \mathrm{hFcRn}{ }^{T g 32}-\mathrm{IFNLR}^{-/-}$mice) 228 and large intestine (3 of $14 \mathrm{hFcRn}{ }^{T g 32}-\mathrm{IFNLR}^{-/-}$mice), $\mathrm{hFcRn}{ }^{T g 32}-\mathrm{IFNLR}^{-/-}$animals had higher levels 229 of virus in all regions of the small intestine including the duodenum (6 of 14 mice), jejunum (6 of 23014 mice), and ileum (4 of 14 mice) (Figure 4A-G). Consistent with more persistent infection in the 
$231 \mathrm{Gl}$ tract of $\mathrm{hFcRn}{ }^{\mathrm{Tg} 32}$-IFNLR ${ }^{-/-}$mice, these mice also contained higher levels of virus in stool (7 of

23214 animals with detectable virus) compared to all other genotypes (Figure 4F). Male animals did

233 contain higher viral titers than did female mice, although these differences were not significant

234 (Supplemental Figure 1C). However, even at 7dpi, we were unable to detect any virus in the

235 blood, liver, pancreas, or brain of any genotype, including hFcRn ${ }^{T g 32}$-IFNLR ${ }^{-/-}$(Supplemental

236 Figure 3A, B, C, \& D). These data show that type III IFNs do not control dissemination but limit

237 persistent infection of the intestinal epithelium.

238 Visualization of intestinal replication of enteroviruses in vivo has been hindered by the lack

239 of sensitive assays to monitor infection with low signal-to-noise. To overcome this limitation, we

240 utilized HCR, a component of which includes signal amplification given the self-assembly of

241 secondary detection hairpins into amplification polymers. We inoculated 7-day old $\mathrm{hFcRn}{ }^{\mathrm{Tg} 32}$ -

$242 \mathrm{IFNAR}^{-{ }^{-}}$and $\mathrm{hFcRn}{ }^{\mathrm{Tg} 32}$-IFNLR ${ }^{-/-}$animals with $10^{6} \mathrm{PFU}$ of E5 by the oral route, sacrificed them at

$2433 \mathrm{dpi}$, and then performed Swiss rolling of full intestinal tissue, which was sectioned and processed

244 for HCR. In contrast to viral titer data, which showed high levels of virus in the intestines of

$245 \mathrm{hFcRn}^{\top \mathrm{g} 32}$-IFNAR ${ }^{-/-}$animals, we did not detect any vRNA in any intestinal section of these animals

246 (Figure 4G). However, we observed clear areas of vRNA-containing cells in various regions of

247 the small intestines of $\mathrm{hFcRn}^{\mathrm{Tg} 32}$-IFNLR ${ }^{-/}$animals (Figure 4G). While vRNA was detected in both

248 the duodenum and jejunum, there were more vRNA-containing cells in the ileum of the $\mathrm{hFcRn}^{\mathrm{Tg} 32}$.

249 IFNLR $^{-/-}$animals (Figure 4G, 4H), suggesting that there may be regional differences in echovirus

250 persistence in the epithelium. Although we observed areas of viral replication within the

251 epithelium, we do not see any damage to the epithelium. A blinded pathologist reviewed H\&Es

252 from uninfected, hFcRn ${ }^{\text {Tg32 }}$ IFNAR $^{-/-}$and $\mathrm{hFCRn}^{T g 32}$ IFNLR $^{-/-}$animals and observed no significant

253 changes or damage to the intestine following 3dpi E5 infection (Supplemental Figure 4A).

254 Additionally, we observed no change to the cellular composition of the epithelium as suggested

255 by Periodic Acid Schiff (PAS) staining for goblet cells (Supplemental Figure 4B) 
We showed previously that echoviruses preferentially infect enterocytes and enteroendocrine cells in human stem cell-derived enteroids ${ }^{9}$. However, whether there is a cell type specificity of infection for echoviruses, or other enteroviruses, in vivo is unknown. To define the cellular tropism of echoviruses in vivo, we designed HCR probes targeting an enterocyte marker (alkaline phosphate intestinal, Alpi), goblet cell marker (mucin-2, Muc2), and enteroendocrine cell marker (chromogranin A, Chga). We confirmed the specificity of these probes in murine-derived intestinal tissue and found that they accurately labeled distinct cell populations in the epithelium (Figure 5A). Using probes directed against E5 and Alpi, Muc2, or Chga, we performed HCR in Swiss rolled intestinal tissue sections isolated from $\mathrm{hFcRn}{ }^{T g 32}$-IFNLR ${ }^{-/-}$animals orally infected with $10^{6}$ E5 at 3dpi. We found that echovirus vRNA exclusively localized to Alpi-positive cells (Figure 5B) and was not observed in any Muc2-positive goblet cells (Figure 5C) or Chga-positive enteroendocrine cells (Figure 5D), as assessed by image analysis and quantification of confocal microscope-generated tile scans of $\sim 4 \mathrm{~mm}^{2}$ of intestinal tissue (Figure 5E and Supplemental

271 Figure 5). These data show that enterocytes are the main targets of echoviruses following oral 272 inoculation of $\mathrm{hFcRn}{ }^{T g} 32-\mathrm{IFNLR}^{-/-}$mice.

\section{Discussion}

275 The events associated with enterovirus infections of the GI tract in vivo are largely unknown. Here,

276 we defined the role of hFcRn and type-specific IFN signaling in mediating echovirus infections of

277 the intestinal epithelium and dissemination to secondary tissue sites. We show that $\mathrm{hFcRn}$ is 278 necessary and sufficient for echovirus infection of the intestinal epithelium in enteroids derived

279 from humanized FcRn mice. However, in vivo, expression of hFcRn alone is not sufficient for 280 echovirus infection by the enteral route. Using humanized FcRn mouse models deficient in either 281 type I or III IFN signaling, we defined the differential roles of these IFNs in echovirus replication 282 in and dissemination from the GI tract. These studies showed that type I IFNs limit dissemination 
of echoviruses from the GI tract and ablation of this signaling robustly increases viral replication at secondary sites, such as the liver. In contrast, type III IFNs suppress replication in the intestinal epithelium and deletion of the receptor for these IFNs prolongs intestinal echovirus replication and increases viral persistence. We further show that echoviruses preferentially infect enterocytes in vivo, which is enhanced in the absence of type III IFN signaling. Collectively, our work presented here provides key insights into the roles of FcRn and IFN signaling in echovirus pathogenesis in the GI tract.

Little is known regarding the mechanisms used by echoviruses to enter the intestinal epithelium. Our data support a model whereby hFcRn is necessary and sufficient for intestinal replication in vitro. While some echoviruses utilize decay accelerating factor (DAF/CD55) as an attachment factor in vitro ${ }^{26}$, E5 does not bind $\mathrm{DAF}^{19}$. Moreover, DAF-binding echoviruses do not bind the murine homolog of $\mathrm{DAF}^{26}$. While a previous study predicted that echovirus binding to DAF might trigger viral internalization and particle delivery to endosomes, at which time FcRnmediated uncoating would occur ${ }^{20}$, the data presented here do not support such a model and suggest that DAF plays no role in echovirus infections of the intestinal epithelium in vitro or in vivo. Instead, our data suggest that FcRn is necessary and sufficient for echovirus infection of the intestinal epithelium and occurs independent of DAF binding. This is consistent with in vivo data from humanized mouse models of DAF, which show that expression of DAF does not impact intestinal replication of DAF-binding variants of $\mathrm{CVB}^{14}$.

FcRn is unique in its ability to mediate the transcytosis of IgG and albumin across the intestinal epithelium. Interestingly, this transport functions in a bidirectional manner in cultured

304 intestinal cell lines, suggesting that FcRn can sample contents from the apical or basolateral 305 domains and mediate the transcytosis of cargo to the opposing domain ${ }^{27}$. This function of FcRn 306 could have important implications during echovirus infections-FcRn could (i) mediate the

307 internalization of viral particles into intracellular compartments that facilitate uncoating and 308 subsequent replication and/or (ii) could mediate the direct transcytosis of viral particles across the 
intestinal epithelium from the lumen into underlying tissue. Given that FcRn mediates bidirectional transport across the epithelium, this raises the possibility that echoviruses could be transported

311 from either the apical or basolateral domains to cross the intestinal barrier. We were unable to

312 visualize active replication in the intestinal epithelium of $\mathrm{hFCRn}{ }^{\top \mathrm{g} 32}$-IFNAR ${ }^{-/-}$animals, despite

313 robust viral dissemination to secondary sites of infection. In contrast, we detected vRNA in $\sim 6 \%$

314 of enterocytes in ileum tissue of $\mathrm{hFCRn}^{\mathrm{Tg} 32}$-IFNLR ${ }^{-/-}$animals, in which there was no dissemination

315 observed. These data suggest that in addition to facilitating viral entry and replication into

316 enterocytes, it is possible that in some cases, FcRn might facilitate the transcytosis of echovirus

317 particles across the epithelium and that ablation of type I IFN signaling promotes dissemination

318 of these particles to secondary sites of infection.

319 Type III IFNs are important in antiviral defenses of many barrier tissues, including the GI

$320 \operatorname{tract}^{28,29}$. For example, IFN- $\lambda$ s control rotavirus infection in the intestinal epithelium in adult and

321 neonatal mice ${ }^{17}$. This study showed that whereas mice lacking IFNLR were more susceptible to

322 rotavirus replication and viral-induced cytotoxicity, IFNAR ${ }^{-/-}$mice were comparable to

323 immunocompetent WT mice. These data are distinct from our work presented here, which shows

324 that type I IFNs are key host mediators that prevent echovirus dissemination following oral

325 infection. Type III IFNs have also been implicated in restricting murine norovirus replication in the

$326 \mathrm{GI}$ tract in vivo ${ }^{16}$. Similar to our findings with echoviruses, IFN- $\lambda$ s restrict persistent norovirus

327 infection whereas type I IFNs restrict dissemination ${ }^{16}$. Previous studies with PV and EV71 suggest

328 that type I IFNs control viral replication of these enteroviruses by the enteral route in vivo ${ }^{12,13}$

329 whereas CVB infection is unchanged in animals deficient in IFNAR ${ }^{14}$. While the mechanistic basis

330 for these differences is unknown, it is possible that the cell-type specific nature of enterovirus

331 replication in the intestine may influence their dependence on IFN signaling. For example, in

332 human enteroids, EV71 preferentially infects goblet cells whereas echoviruses are enriched in 333 enterocytes ${ }^{9,10}$. In cell lines, previous work has suggested that PV transcytoses across $\mathrm{M}$ cells , 
334 suggesting it does not replicate in the epithelium ${ }^{30}$. Future studies on the cell-type specific nature of IFN signaling in distinct lineages of intestinal cells and the impact of these differences on enterovirus replication will be essential to determine if the distinct cellular tropism of enteroviruses in the GI tract influences IFN-mediated signaling.

Our findings presented here define fundamental aspects of echovirus biology that enhance our understanding of how infection, tissue targeting, and disease occurs in vivo. We

340 show that FcRn is necessary but not sufficient for echovirus infections of the GI tract in vivo and

341 that type I and III IFNs differentially control echovirus persistence and dissemination. Collectively,

342 these studies provide new insights into echovirus biology and the development of in vivo 343 models that recapitulate distinct aspects of echovirus disease, which could potentially accelerate the development of therapies.

Materials and Methods

347 Cell lines and viruses. HeLa cells (clone 7B) were provided by Jeffrey Bergelson, Children's 348 Hospital of Philadelphia, Philadelphia, PA, and cultured in MEM supplemented with 5\% FBS, non349 essential amino acids, and penicillin/streptomycin. Experiments were performed with echovirus 5 350 (Noyce strain, E5), which was obtained from the ATCC. Virus was propagated in HeLa cells and 351 purified by ultracentrifugation over a $30 \%$ sucrose cushion, as described previously ${ }^{31}$. Enteroid 352 experiments were performed with light-sensitive neutral red (NR) incorporated viral particles. E5 353 was propagated in the presence of $\mathrm{NR}(10 \mu \mathrm{g} / \mathrm{mL})$ in semi-dark conditions and was subsequently 354 purified in semi-dark conditions by ultracentrifugation over a sucrose cushion ${ }^{32}$. All viruses were 355 sequenced for viral stock purity following propagation. Purity of all viral stocks was confirmed by 356 Sanger sequencing of VP1 using enterovirus-specific primers ${ }^{33}$. Briefly, RNA extraction was 357 performed on $10 \mu \mathrm{l}$ of purified virus stock, according to manufacturer's instructions (Qiagen Cat. 358 529904). RNA was reverse transcribed using SuperScript III reverse transcription kit, (Invitrogen 359 cat. 18080093) according to manufacturer's instructions, with a pan enterovirus primer (vir21; 
for 20 minutes. PCR was performed with $5 \mu$ of the cDNA reaction using BioRad iTaq DNA polymerase (BioRad cat. 1708870). Virus specific primers were as follows: E5 forward 5'TATCGCCAATTACAACGCGAA-3'; E5 reverse 5'-TTGGTTTGAAGTAAACCCTTA-3'.

Animals. All animal experiments were approved by the Duke University Animal Care and Use Committees, and all methods were performed in accordance with the relevant guidelines and

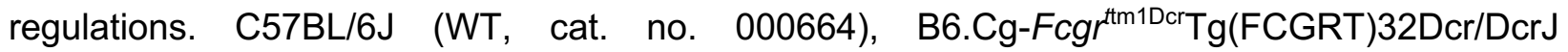
(hFcRn ${ }^{T g 32}$, cat. no. 014565), and B6.(Cg)-Ifnar1 ${ }^{\text {tm1.2Ees } / J ~(I F N A R ~}{ }^{-/}$, cat. no. 028288) mice were purchased from The Jackson Laboratory. $\mathrm{hFcRn}^{\mathrm{Tg} 32}$-IFNAR ${ }^{-/-}$mice were generated as described previously ${ }^{21}$. B6.Ifnlr ${ }^{-/} / \mathrm{J}\left(\mathrm{IFNLR}^{-/-}\right)$mice were provided by Dr. Megan Baldridge (Washington University School of Medicine). hFcRn ${ }^{\top g 32}$-IFNLR ${ }^{-/-}$mice were generated by crossing B6.Cg-

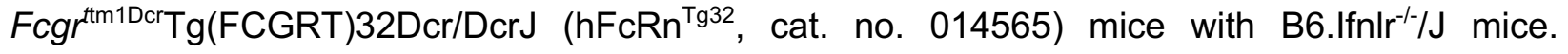
Breeders were established that were deficient in mouse FcRn and IFNLR and were homozygous for the hFcRn transgene. All animals used in this study were genotyped by Transnetyx.

Enteroid isolation and passaging. Murine intestinal crypts were isolated using a protocol adapted from Stem Cell Technologies. Briefly, intestines were isolated from five 10-day old pups and connective tissue removed. Intestines were cut longitudinally and washed extensively in PBS. Intestines were cut into $5 \mathrm{~mm}$ segments and washed again using a $10 \mathrm{~mL}$ serological pipette until

380 PBS was clear. Washed intestinal pieces were incubated in gentle cell dissociation reagent (Stem 381 Cell Technologies Cat. 07174) for 15 minutes at room temperature. Crypts were released using

$3820.1 \%$ BSA and vigorous pipetting with a $10 \mathrm{~mL}$ serological pipette. Crypts were filtered using a $38370 \mu \mathrm{m}$ cell strainer and the resulting flow through centrifuged at $290 \mathrm{xg}$ for 5 minutes. Pellets were 384 resuspended in Matrigel (Corning Cat. 356231) and 40 $\mu \mathrm{L}$ of crypt-containing Matrigel 'domes' 385 plated into each well of a 24 well plates (Corning 3526 ), placed in a $37^{\circ} \mathrm{C}$ incubator to pre- 
polymerize for $\sim 3 \mathrm{~min}$, turned upside-down to ensure equal distribution of the isolated cells in domes for another $10 \mathrm{~min}$, then carefully overlaid with $500 \mu \mathrm{L}$ IntestiCult Organoid Growth Medium (Stem Cell Technologies Cat. 06005) supplemented with 1\% penicillin/streptomycin, $50 \mu \mathrm{g} / \mathrm{mL}$ gentamycin, and $0.2 \%$ amphotericin b, containing Y-27632 (Rock inhibitor, Sigma). Media was changed every $48 \mathrm{hrs}$ and $\mathrm{Y}-27632$ was removed after the first media change. pipette tip in PBS and centrifuged at $400 \times x$ for 5 minutes. The enteroid-containing pellet were resuspended in TrypLE (Invitrogen Cat. 12605010) and incubated in a water bath at $37^{\circ} \mathrm{C}$ for 8

394 minutes. Enzyme activity was quenched with DMEM containing 10\% FBS and centrifuged at $395400 x g$ for 5 minutes. Pellets were resuspended in Matrigel and 40 $\mathrm{L}$ Matrigel domes in each well of a 24 well plate. Domes were allowed to solidify at $37^{\circ} \mathrm{C}$ for 10 minutes and then covered with IntestiCult Organoid Growth Medium, as described above. For infections, crypts were plated in 24-well plates pre-coated with 15uL of Matrigel using a P1000 tip and allowed to solidify for 30 minutes.

Enteroid Infections. Enteroids plated on Matrigel coating as described above were allowed to 402 differentiate for 5 days with media replaced every $48 \mathrm{hrs}$. For infections, wells were infected with $40310^{6}$ PFU of NR-incorporated virus, generated as described above. Virus was pre-adsorbed for 1 404 hour at $16^{\circ} \mathrm{C}$, enteroids washed three times with PBS, and media replaced. Infections were 405 initiated by shifting enteroids to $37^{\circ} \mathrm{C}$. At $6 \mathrm{hpi}$, enteroids were exposed to light on a light box for 40620 minutes to render intact viral particles non-infectious and infections performed for the times 407 indicated. Plaque assays were performed in HeLa cells overlayed with $1: 1$ mixture of $1 \%$ agarose 408 and 2x MEM (4\% FBS, 2\% pen/strep, 2\% NEAA). Plaques were enumerated 40hpi by crystal 409 violet staining. 
411 RNA extraction and RNAsequencing. Total RNA was prepared using the Sigma GenElute total

412 mammalian RNA miniprep kit with optional DNase step, according to the protocol of the

413 manufacturer. RNA quality was assessed by Nanodrop and an Agilent RNA Screen Tape System,

414 and 1ug was used for library preparation using RNA with Poly A selection kit (Illumina), as per the

415 manufacturer's instructions. Sequencing was performed on an Illumina HiSeq. RNA-seq FASTQ

416 data were processed and mapped to the mouse reference genome (GRCm38) using CLC

417 Genomics Workbench 20 (Qiagen). Differential gene expression was performed using the

418 DESeq2 package in $\mathrm{R}^{34}$. Heatmaps and volcano plots were made in GraphPad Prism 9. Raw

419 sequencing files have been deposited in Sequence Read Archives.

421 Suckling pup infections. 7-day-old mice were inoculated by the oral route with $10^{6}$ PFU of E5.

422 Oral gavage inoculation was performed using a $1 \mathrm{~mL}$ disposable syringe and a 24-gauge round

423 tipped needle in $50 \mu \mathrm{L}$ of $1 \mathrm{X}$ PBS. Mice were euthanized at either 3- or 7-days post inoculation

424 and organs harvested into $0.5 \mathrm{~mL}$ of DMEM and stored at $-80^{\circ} \mathrm{C}$. Tissue samples for viral titration

425 were thawed and homogenized with a TissueLyser LT (Qiagen) for 5 minutes, followed by brief

426 centrifugation for 5 minutes at $8000 x g$. Viral titers in organ homogenates were determined by

427 TCID50 in HeLa cells and enumerated following crystal violet staining.

428

429 HCR and Imaging. HCR was performed following the Molecular Instruments HCR v3.0 protocol

430 for FFPE human tissue sections ${ }^{24,25}$. Briefly, tissue sections were deparaffinized with xylene and 431 rehydrated with decreasing concentrations of ethanol (100\%, 95\%, 80\%). Antigen unmasking was

432 performed with slides submerged in $10 \mathrm{mM}$ citrate buffer $(\mathrm{pH}$ 6.0) and heated in a steamer for 20

433 minutes at $\sim 90^{\circ} \mathrm{C}$. Slides were cooled to room temperature. Sections were treated with $10 \mu \mathrm{g} / \mathrm{mL}$

434 Proteinase $\mathrm{K}$ for $10 \mathrm{~min}$ at $37^{\circ} \mathrm{C}$ and washed with RNase free water. Samples were incubated for

43510 minutes at $37^{\circ} \mathrm{C}$ in hybridization buffer. Sections were incubated overnight in a humidified 436 chamber at $37^{\circ} \mathrm{C}$ with 3 pmol of initiator probes in hybridization buffer. We designed probes for 
438 in house. Custom probes for Alpi were designed by Molecular Instruments (Lot PRI910). The next

439 day, slides were washed in probe wash buffer and 5x SSCT for 4x 15 min, according to the

440 manufacturer's instructions. Samples were incubated in a humidified chamber at $37^{\circ} \mathrm{C}$ for 30

441 minutes in amplification buffer. Fluorescent hair pins were heated to $95^{\circ} \mathrm{C}$ for 90 seconds and

442 snap cooled at room temperature for $30 \mathrm{~min}$. Hairpins and amplification buffer were added to the

443 sample and incubated overnight at room temperature. Hairpins were washed off with 5x SSCT

444 for 5 minutes, 15 minutes, 15 minutes, and 5 minutes followed by a wash with PBS containing

445 DAPI. Slides were mounted in vectashield with DAPI. Slides were imaged on a Zeiss 880 with

446 Airyscan inverted confocal microscope. Tile scans were performed at a $20 x$ magnification using

447 a 6 by 6 square area resulting in 36 total images. Each intestinal segment was tile scanned using

448 three different areas for quantification. Image analysis was performed using FIJI.

450 Periodic Acid Schiff (PAS) staining. PAS staining was performed according to manufactures 451 instructions (Abcam, ab150680). Slides were mounted with Cytoseal 60 (Thermo Scientific, 452 83104). Images were captured on an IX83 inverted microscope (Olympus) using a UC90 color 453 CCD camera (Olympus).

455 Statistics. All statistical analysis was performed using GraphPad Prism version 8. Data are 456 presented as mean \pm SD. A one-way ANOVA was used to determine statistical significance, as 457 described in the figure legends. Parametric tests were applied when data were distributed 458 normally based on D'Agostino-Pearson analyses; otherwise, nonparametric tests were applied. $459 P$ values of $<0.05$ were considered statistically significant, with specific $P$ values noted in the 460 figure legends. 
463 We thank Cristian Ovies for technical assistance (Duke University), Megan Baldridge 464 (Washington University) for providing IFNLR ${ }^{-/-}$mice, and Sujan Shresta (La Jolla Institute for 465 Immunology) for providing hFcRn ${ }^{T g 32}$-IFNAR ${ }^{-/-}$mice. This project was supported by NIH R01466 Al150151 (C.B.C), NIH T32-AI060525 (A.I.W), NIH F31-Al149866 (A.I.W). The funders had no 467 role in study design, data collection and analysis, decision to publish, or preparation of the 468 manuscript. 


\section{Literature cited}

471 1. Civardi, E. et al. Viral outbreaks in neonatal intensive care units: What we do not know.

$472 \quad$ Am. J. Infect. Control 41, 854-856 (2013).

473 2. Naing, Z. et al. Prevalence of viruses in stool of premature neonates at a neonatal

$474 \quad$ intensive care unit. J. Paediatr. Child Health 49, (2013).

475 3. Verboon-Maciolek, M. A., Krediet, T. G., Gerards, L. J., Fleer, A. \& Van Loon, T. M.

476 Clinical and epidemiologic characteristics of viral infections in a neonatal intensive care

477 unit during a 12-year period. Pediatr. Infect. Dis. J. 24, 901-904 (2005).

$4784 . \quad$ Isaacs, D. et al. Conservative Management of an Echovirus 11 Outbreak in a Neonatal

$479 \quad$ Unit. Lancet 333, 543-545 (1989).

480 5. Abedi, G. R., Watson, J. T., Nix, W. A., Oberste, M. S. \& Gerber, S. I. Morbidity and Mortality Weekly Report Enterovirus and Parechovirus Surveillance-United States, 20142016. MMWR. Morb. Mortal. Wkly. Rep. 67, 515-18 (2018).

6. Bubba, L. et al. A 4-year Study on Epidemiologic and Molecular Characteristics of Human Parechoviruses and Enteroviruses Circulating in Children Younger Than 5 Years in Northern Italy. Pediatr. Infect. Dis. J. 36, 13-19 (2017).

7. Cabrerizo, M. et al. Molecular epidemiology of enterovirus and parechovirus infections according to patient age over a 4-year period in Spain. J. Med. Virol. 89, 435-442 (2017).

8. Rodà, D. et al. Clinical characteristics and molecular epidemiology of Enterovirus infection in infants $<3$ months in a referral paediatric hospital of Barcelona. Eur. J. Pediatr. 174, 1549-1553 (2015).

9. Drummond, C. G. et al. Enteroviruses infect human enteroids and induce antiviral

493 10. Good, C., Wells, A. I. \& Coyne, C. B. Type III interferon signaling restricts Enterovirus 71 494 infection of goblet cells. Sci. Adv. 5, 1-11 (2019).

495 11. Mahlakõiv, T., Hernandez, P., Gronke, K., Diefenbach, A. \& Staeheli, P. Leukocyte- 

doi:10.1371/journal.ppat.1004782.

12. Khong, W. X. et al. A Non-Mouse-Adapted Enterovirus 71 (EV71) Strain Exhibits Neurotropism, Causing Neurological Manifestations in a Novel Mouse Model of EV71 Infection. J. Virol. 86, 2121-2131 (2012).

13. Ohka, S. et al. Establishment of a Poliovirus Oral Infection System in Human Poliovirus Receptor-Expressing Transgenic Mice That Are Deficient in Alpha/Beta Interferon Receptor. J. Virol. 81, 7902-7912 (2007).

14. Pan, J. et al. Expression of Human Decay-Accelerating Factor on Intestinal Epithelium of Transgenic Mice Does Not Facilitate Infection by the Enteral Route. J. Virol. 89, 4311-

15. Baldridge, M. T. et al. Expression of IfnIr1 on Intestinal Epithelial Cells Is Critical to the (2017).

16. Nice, T. J. et al. Interferon Lambda cures persistent murine norovirus infection in the

513 17. Pott, J. et al. IFN- $\lambda$ determines the intestinal epithelial antiviral host defense. PNAS 108, 7944-7949 (2011).

515 18. Nice, T. J. et al. Type I Interferon Receptor Deficiency in Dendritic Cells Facilitates Pathog. 12, 1-19 (2016).

19. Morosky, S. et al. The neonatal Fc receptor is a pan-echovirus receptor. Proc. Natl. Acad.

520 20. Zhao, X. et al. Human Neonatal Fc Receptor Is the Cellular Uncoating Receptor for $521 \quad$ Enterovirus B. Cell 177, 1553-1565.e16 (2019). 
522 21. Wells, A. I. et al. Human FcRn expression and Type I Interferon signaling control

523 Echovirus 11 pathogenesis in mice. PLOS Pathog. 17, e1009252 (2021).

524 22. Knudsen Sand, K. M. et al. Unraveling the interaction between FcRn and albumin:

525 Opportunities for design of albumin-based therapeutics. Front. Immunol. 6, 1-21 (2015).

526 23. Roopenian, D. C., Christianson, G. J., Proetzel, G. \& Sproule, T. J. Human FcRn

527 Transgenic Mice for Pharmacokinetic Evaluation of Therapeutic Antibodies. Methods Mol.

528 Biol. 1438, 103-114 (2016).

529 24. Choi, H. M. T. et al. Mapping a multiplexed zoo of mRNA expression. Dev. 143, 3632-

$530 \quad 3637(2016)$.

531 25. Choi, H. M. T. et al. Third-generation in situ hybridization chain reaction: Multiplexed,

532 quantitative, sensitive, versatile, robust. Dev. 145, 1-10 (2018).

533 26. Bergelson, J. M. et al. Decay-accelerating factor (CD55), a glycosylphosphatidylinositol-

S A 91, 6245-6248 (1994).

27. Dickinson, B. L. et al. Bidirectional FcRn-dependent IgG transport in a polarized human intestinal epithelial cell line. J. Clin. Invest. 104, 903-911 (1999).

28. Wells, A. I. \& Coyne, C. B. Type III Interferons in Antiviral Defenses at Barrier Surfaces.

Trends Immunol. 39, 848-858 (2018).

29. Schoggins, J. W. Interferon-Stimulated Genes: What Do They All Do? Annu. Rev. Virol.

542 30. Ouzilou, L. et al. Poliovirus transcytosis through M-like cells. J. Gen. Virol. 83, 2177-2182 $543 \quad$ (2002).

544 31. Morosky, S., Lennemann, N. J. \& Coyne, C. B. BPIFB6 Regulates Secretory Pathway 545 Trafficking and Enterovirus Replication. J. Virol. 90, 5098-5107 (2016).

546 32. Crowther, D. \& Melnick, J. L. The incorporation of neutral red and acridine orange into 547 developing poliovirus particles making them photosensitive. Virology 14, 11-21 (1961). 
548 33. Oberste, M. S., Nix, W. A., Maher, K. \& Pallansch, M. A. Improved molecular

549 identification of enteroviruses by RT-PCR and amplicon sequencing. J. Clin. Virol. 26,

$550 \quad 375-377$ (2003).

551 34. Love, M. I., Huber, W. \& Anders, S. Moderated estimation of fold change and dispersion

552 for RNA-seq data with DESeq2. Genome Biol. 15, 1-21 (2014).

553

554

555

556

557

558

559

560

561

562

563

564

565

566

567

568

569 
Figure 1

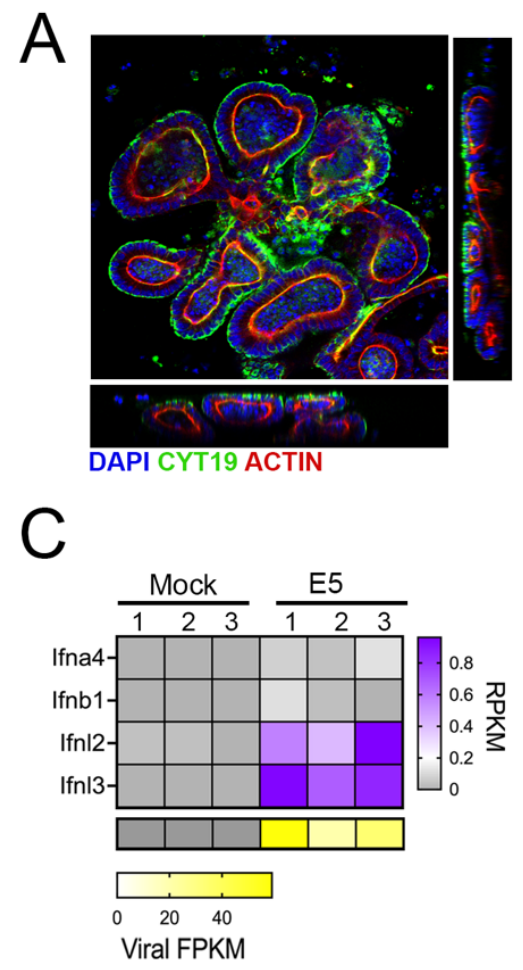

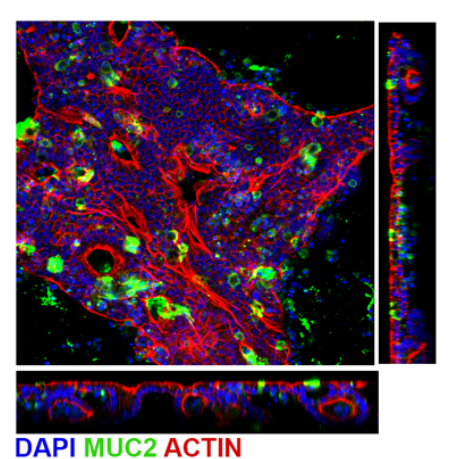
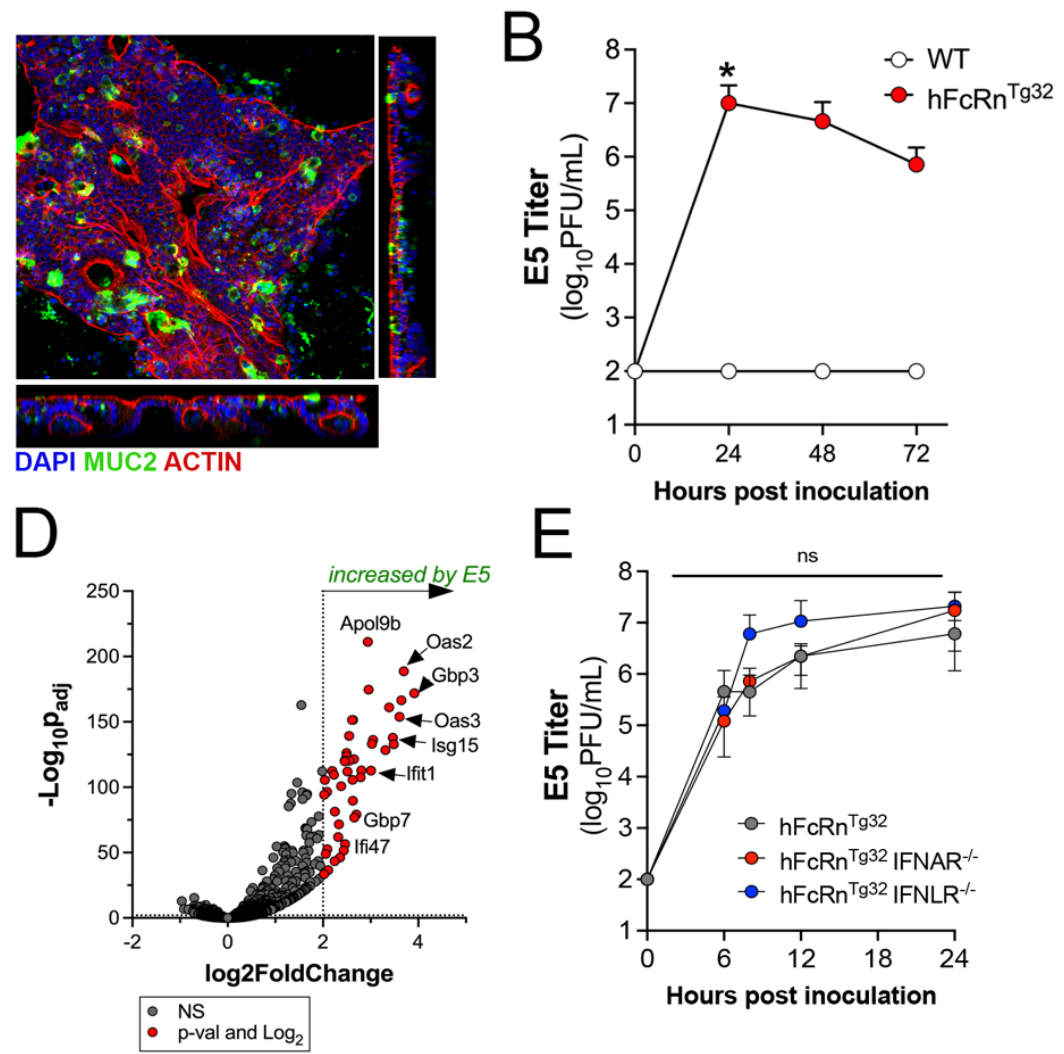

Figure 1. Human FcRn is necessary and sufficient for echovirus infection of murinederived primary enteroids. (A) Murine enteroids were generated $\mathrm{Lgr}^{+}$crypts isolated from the small intestines of five 10-day old neonatal C57BL/6J (WT) mice. Confocal microscopy of enteroids immunostained with cytokeratin-19 in green and actin in red (left) or mucin-2 in green and actin in red (right) 10-days post-culturing. (B) WT (white) or $\mathrm{hFcRn}{ }^{\text {Tg32 }}$ (grey) enteroids were generated from small intestine tissue from 10-day old neonatal mice and infected with $10^{6}$ PFU of neutral red incorporated E5. Viral titers $\left(\log _{10} \mathrm{PFU} / \mathrm{mL}\right)$ were assessed in cell culture supernatants at the indicated time points. (C) Heatmap of RPKM values of the type I IFNs Ifna4 and Ifnb1 and the type III IFNs Ifnl2 and Ifnl3 from bulk RNASeq of uninfected (mock)- or E5 infected hFcRn ${ }^{\text {Tg332 }}$ enteroids at $24 \mathrm{hrs}$ post-infection. Key at right, purple indicates higher reads and grey denotes no reads detected. At bottom, viral FPKM values from samples shown at top. Yellow indicates high viral RNA reads and grey denotes no reads detected. (D) Volcano plot comparing differentially expressed transcripts in $\mathrm{E} 5$ infected $\mathrm{hFcRn}{ }^{T g 32}$ enteroids compared to mock controls as determined by DeSeq2 analysis. Grey circles represent genes whose expression was not significantly changed. Red circles represent genes that were significantly changed by E5 infection. Significance was set at $a p<0.01$ and a $\log _{2}$ fold-change of \pm 2 . (E) Enteroids generated from the small intestine of $\mathrm{hFcRn}{ }^{\top \mathrm{g} 32}$ (grey), $\mathrm{hFcRn}^{\mathrm{Tg} 32}$-IFNAR $^{-/-}$(red), or hFcRn ${ }^{\mathrm{Tg} 32}$-IFNLR $^{-/-}$(blue) were infected with $10^{6}$ PFU of neutral red incorporated E5. Viral titers $\left(\log _{10} P F U / \mathrm{mL}\right)$ are shown at indicated time points. In $(B)$ and $(E)$, data are shown as mean \pm standard deviation from three independent replicates. Enteroids were isolated from at least five 10-day old neonatal mice and were pooled together during the LGR5 ${ }^{+}$crypt isolation. Significance in B was determined by a Kruskal-Wallis test with a Dunn's test for multiple comparisons. Significance in D was determined using a two-way ANOVA with a Geisser-Greenhouse correction and a Tukey's multiple comparisons test. ( ${ }^{*} \mathrm{p}<0.05$, ns not significant.) 
A

\begin{tabular}{|c|c|c|c|c|}
\hline \multirow{2}{*}{ Strain } & \multicolumn{4}{|c|}{ Expression } \\
\hline & mFcRn & $\mathrm{hFcRn}$ & IFNAR & IFNLR \\
\hline C57BL/6J & + & - & + & + \\
\hline $\mathrm{hFCRn}^{\mathrm{T}} 32 \mathrm{2}$ & - & + & + & + \\
\hline IFNAR $^{-1}$ & + & - & - & + \\
\hline $\mathrm{hFCRn}{ }^{\mathrm{T} 932}-\mathrm{IFNAR}^{-1-}$ & - & + & - & + \\
\hline IFNLR $^{-1-}$ & + & - & + & - \\
\hline $\mathrm{hFCRn}^{\mathrm{Tg} 32}-\mathrm{IFNLR}{ }^{-1-}$ & - & + & + & - \\
\hline
\end{tabular}

B

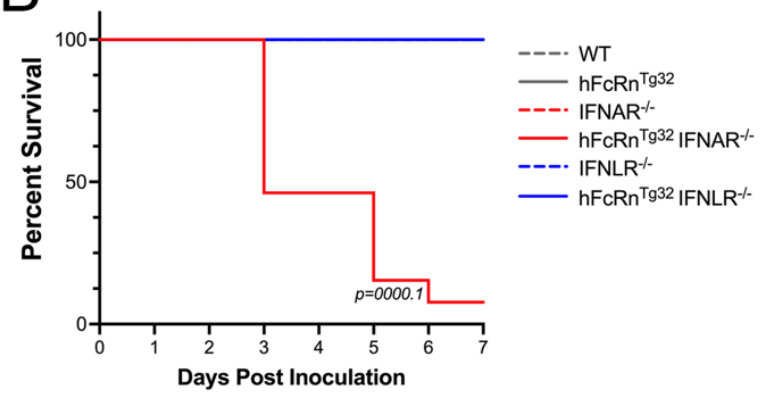

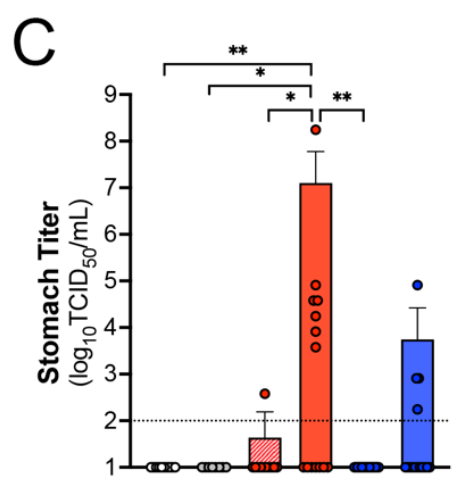

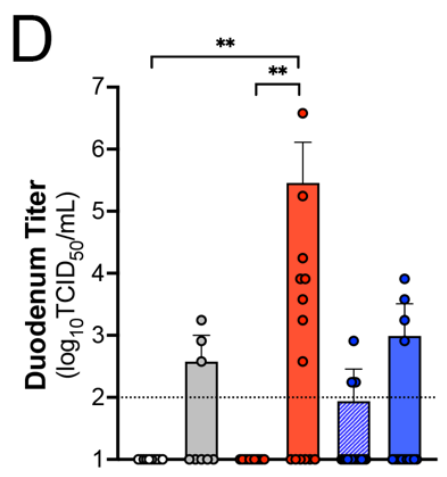

$\mathrm{E}$
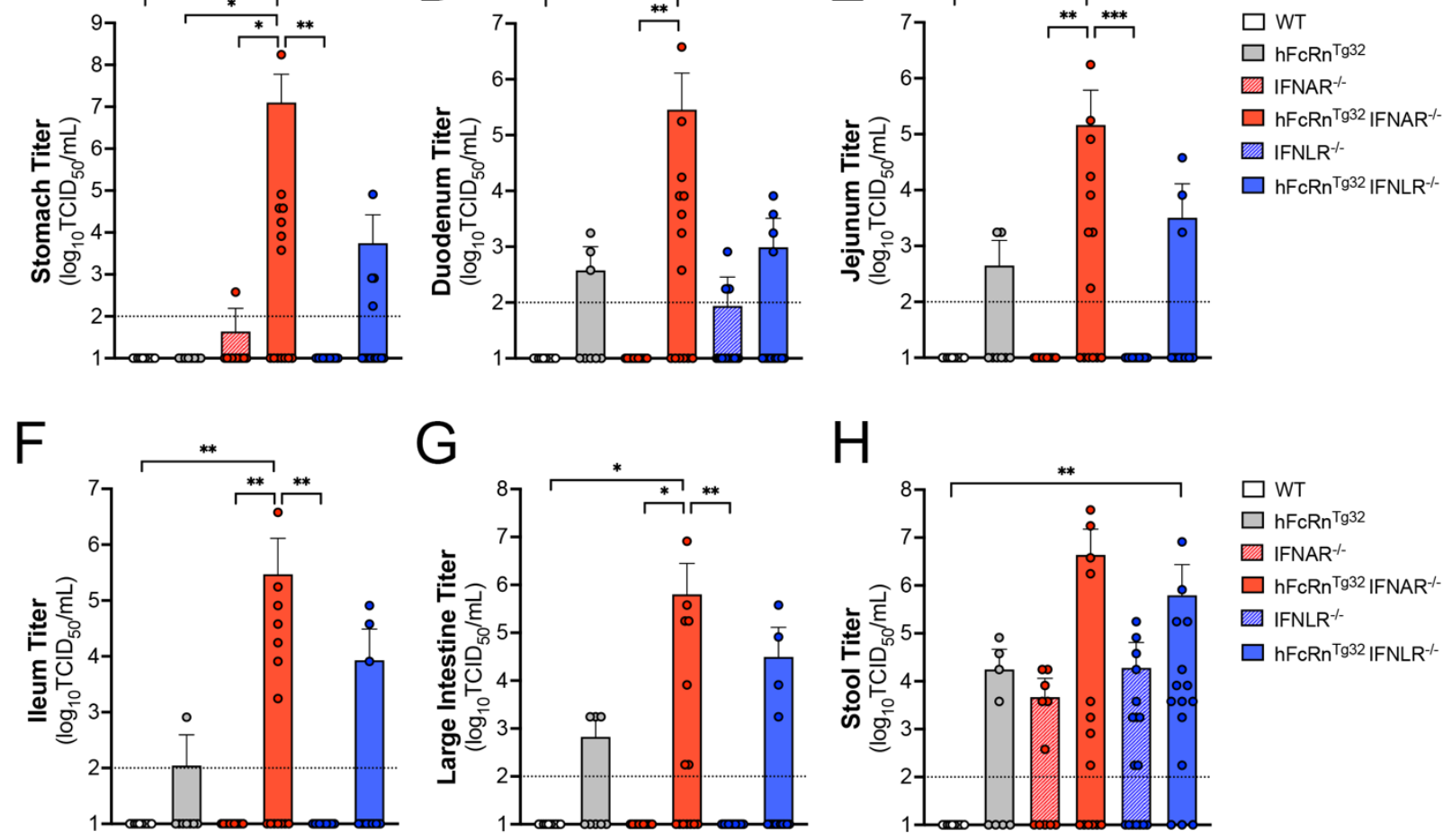

G

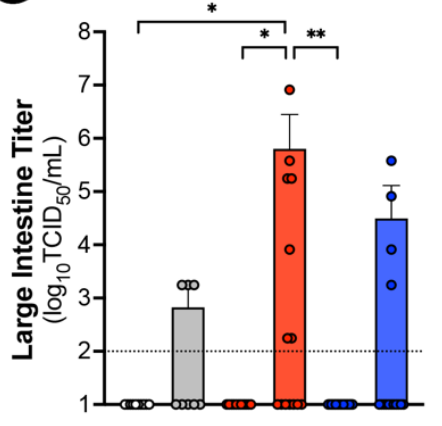

$\mathrm{H}$

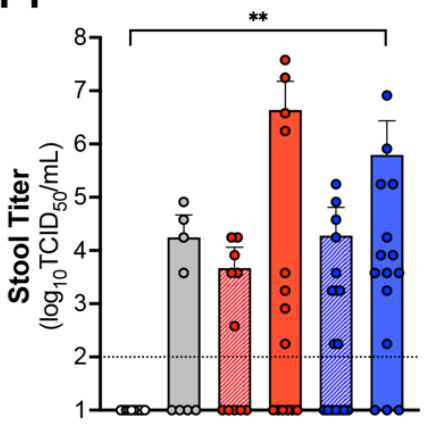

$\square$ WT

$\square \mathrm{hFcRn}^{\mathrm{Tg} 32}$

罝 IFNAR ${ }^{-1}$

$\square \mathrm{hFcRn}{ }^{\text {Tg } 32}$ IFNAR $^{-/-}$

四 IFNLR ${ }^{-1}$

$\square \mathrm{hFcRn}^{\text {Tg } 32}$ IFNLR $^{-/}$

Figure 2. Expression of human FcRn is not sufficient for echovirus infection by the enteral route in vivo. (A) Table of the six genotypes used in this study. Shown is the expression of mouse or human FcRn, IFNAR, and IFNLR amongst these genotypes. (B) Survival of the indicated genotype of mice inoculated with $10^{6} \mathrm{E} 5$ by oral gavage for 7 days post-inoculation. The log-rank test was used to analyze the statistical difference of the survival rate. (C-H). At 3dpi, animals were sacrificed and viral titers in stomach (C), duodenum (D), jejunum (E), ileum (F), large intestine (G), and stool (H) determined by TCID50 assays. In all, titers are shown as $\log _{10} \mathrm{TCID} 50 / \mathrm{mL}$ with the limit of detection indicated by a dotted line. Data are shown as mean \pm standard deviation with individual animals shown as each data point. Data are shown with significance determined with a 
A

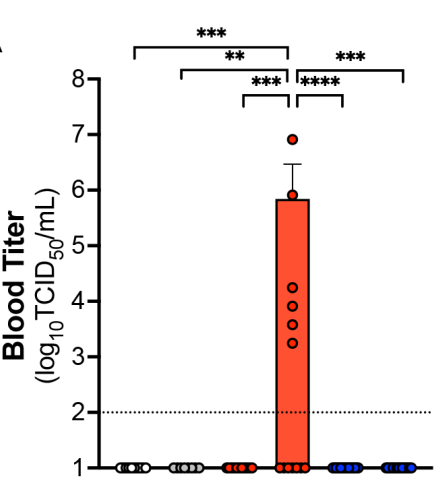

$\mathcal{C}$

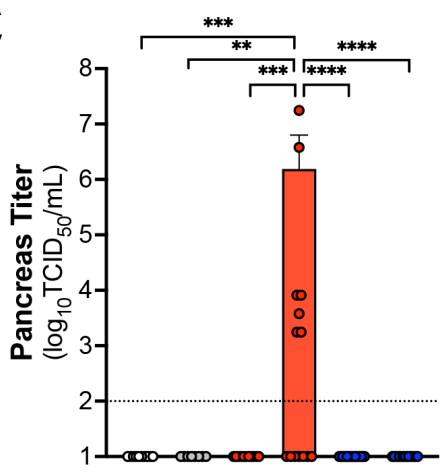

B

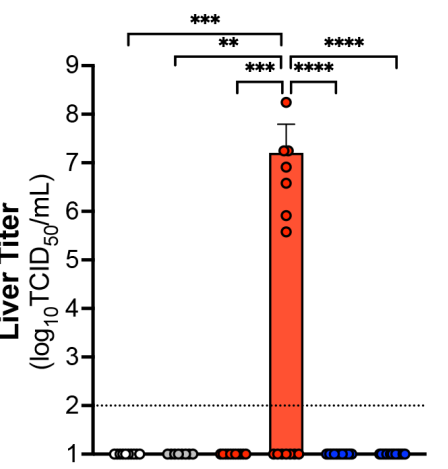

$D$

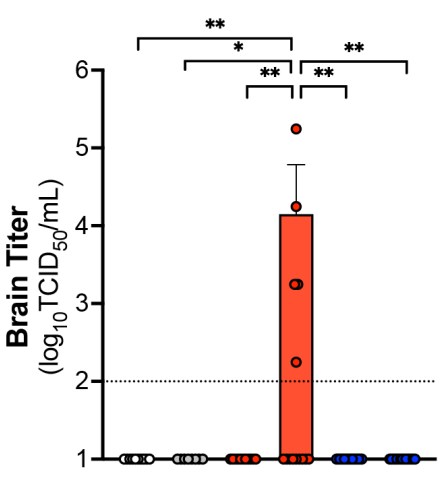

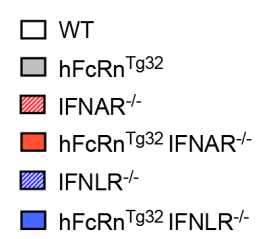

$\square$ WT

$\square \mathrm{hFcRn}^{\text {Tg } 32}$

IFNAR ${ }^{-1-}$

$\square \mathrm{hFcRn}^{T \mathrm{Tg} 32} \mathrm{FNAR}^{-1-}$

IFNLR ${ }^{-1-}$

$\square \mathrm{hFcRn}{ }^{\top \mathrm{g} 32} \mathrm{FFNLR}^{-/-}$

E
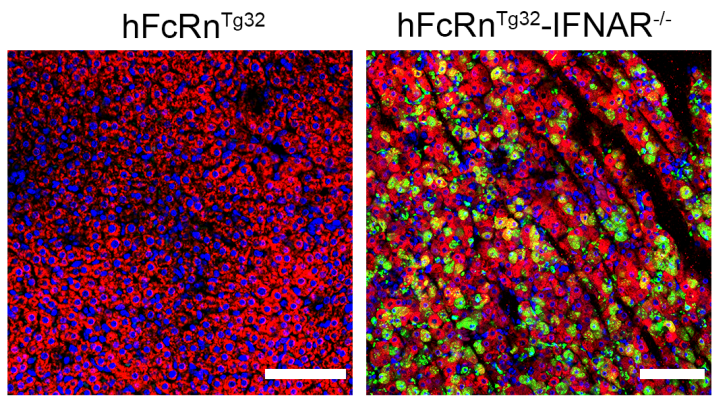

hFcRn ${ }^{\text {Tg32 }}$ IFNLR $^{-/-}$

DAPI vRNA Albumin

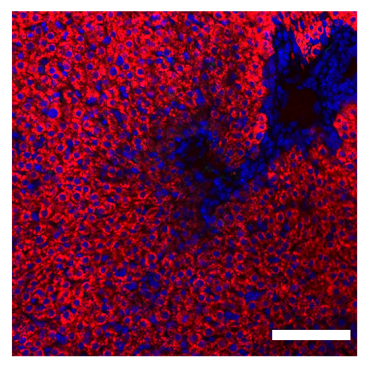

Figure 3. Type I IFNs control echovirus dissemination from the GI tract. 7-day old pups were orally inoculated with $10^{6} \mathrm{PFU}$ of E5 and at 3dpi, sacrificed for viral titration and histology. (A-D), Viral titers in the blood (A), liver (B), pancreas (C), and brain (D) are shown. In all, titers are shown as $\log _{10} \mathrm{TCID} 50 / \mathrm{mL}$ with the limit of detection indicated by a dotted line. Data are shown as mean \pm standard deviation with individual animals shown as each data point. (E) Hybridization chain

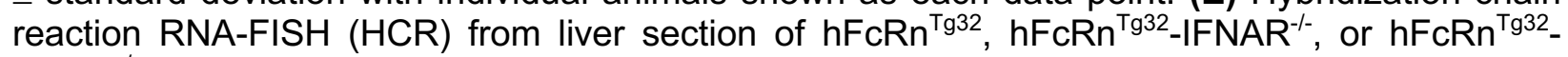
$\mathrm{IFNLR}^{-1-}$ neonatal mice at $3 \mathrm{dpi}$ using probes against the $\mathrm{E} 5$ genome (green) and albumin (red). DAPI-stained nuclei are shown in blue. Scale bars shown at bottom right $(100 \mu \mathrm{m})$. In A-D, data are shown with significance determined with a Kruskal-Wallis test with a Dunn's test for multiple comparisons $\left({ }^{*} p<0.05,{ }^{* *} p<0.005,{ }^{* * *} p<0.0005,{ }^{* * * *} p<0.0001\right)$. 
Figure 4
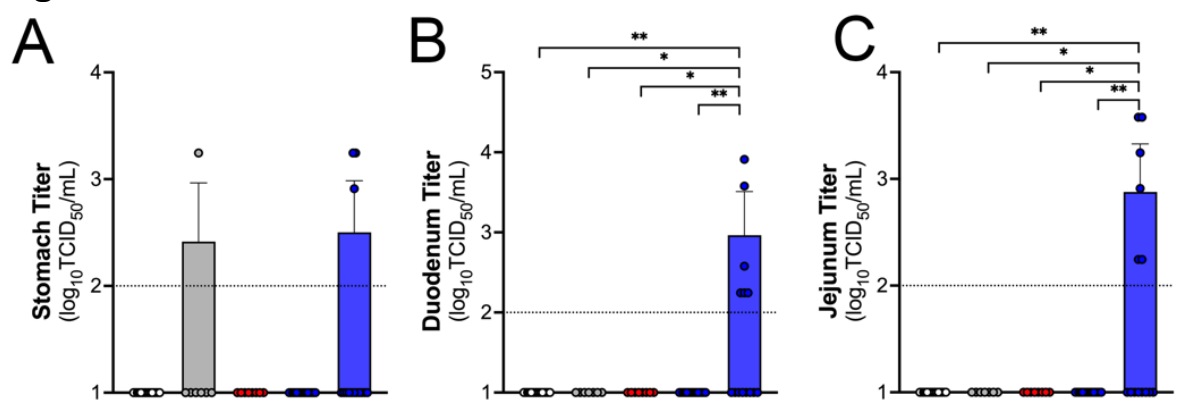

$$
\begin{aligned}
& \square \text { WT } \\
& \square \text { hFcRn }^{\text {Tg32 }} \\
& \mathbb{Z} \text { IFNAR }^{-/-} \\
& \mathbb{Z} \text { IFNLR }^{-1} \\
& \square \text { hFcRn }^{\text {Tg32 }} \text { IFNLR }^{-1}
\end{aligned}
$$
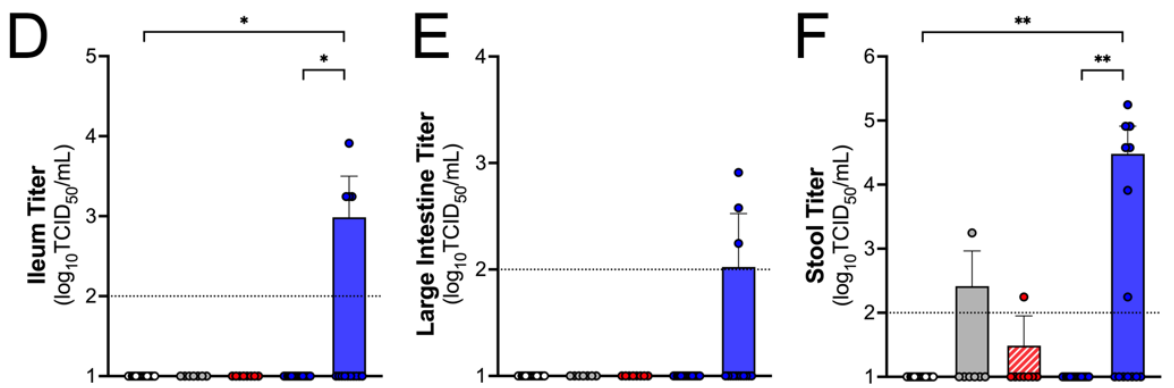

$\square W T$

$\square \mathrm{hFCRn}^{\mathrm{T} 932}$

四 IFNAR ${ }^{-1}$

四 IFNLR ${ }^{-1}$

$\square \mathrm{hFcRn}^{\mathrm{T}}{ }^{\mathrm{T} 32} \mathrm{FFNLR}^{-1}$

G

No probes control hFcRn $^{\top 932}$-IFNAR ${ }^{-1-}$ hFcRn $^{\top 932}$ IFNLR $^{-1}$

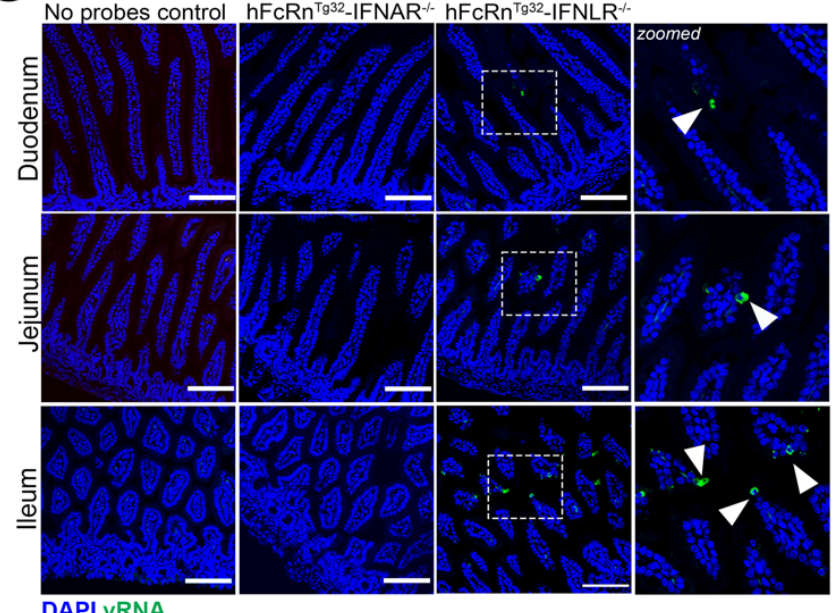

$\mathrm{H}$

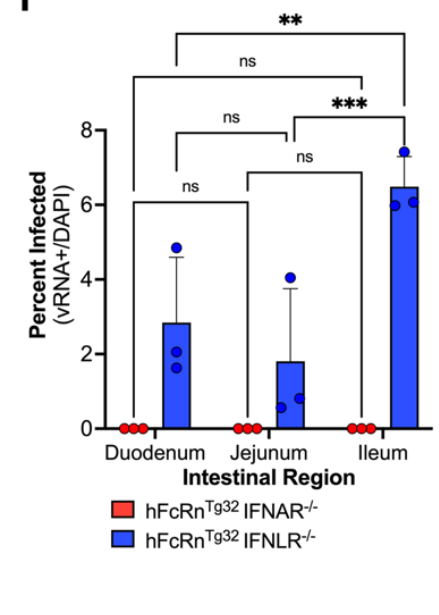

Figure 4. Type III IFNs restrict persistent echovirus infection in the GI epithelium. 7-day old neonatal were orally inoculated with $10^{6} \mathrm{PFU}$ of E5 and at $7 \mathrm{dpi}$, animals were sacrificed for viral titration and tissue collection. (A-F), Viral titers are shown in stomach (A), duodenum (B), jejunum (C), ileum (D), large intestine (E), and stool (F). In all, titers are shown as $\log _{10} \mathrm{TCID} 50 / \mathrm{mL}$ with the limit of detection indicated by a dotted line. Data are shown as mean \pm standard deviation with individual animals shown as each data point. Significance was determined using a Kruskal-Wallis test with a Dunn's test for multiple comparisons $\left({ }^{*} p<0.05,{ }^{* *} p<0.005\right)$. (G) At $3 \mathrm{dpi}$, animals were sacrificed and the entire GI tract was removed and swiss rolled following by histologic sectioned. $\mathrm{HCR}$ of $\mathrm{hFcRn}{ }^{\text {Tg32 }}$ IFNAR $^{-1-}$ or $\mathrm{hFCRn}^{\text {Tg32 }}$ IFNLR $^{-1-}$ pups at the 3dpi using probes against the $\mathrm{E} 5$ genome (green) and DAPI (blue). Scale bars shown at bottom right $(100 \mu \mathrm{m})$. Zoom of specific regions in $\mathrm{hFCRn}^{T \mathrm{~g} 32} \mathrm{IFNLR}^{-/-}$images are shown to the right. (H) Quantification of three independent tile scans using confocal microscopy of each region of the small intestines based on the number of villi that were positive for vRNA using the cell count function in FIJI. Data are shown 
645 as percent of vRNA positive villi over total villi per tile scan. Three independent tile scans were 646 quantified (for an average of 144 villi in the duodenum, 224 villi in the jejunum, and 164 villi in the 647 ileum). Significance was determined by a Two-way Anova with Šídák's multiple comparisons tests $648 \quad\left({ }^{*} p<0.05,{ }^{* *} p<0.005,{ }^{* * *} p<0.0005,{ }^{* * *} p<0.0001\right)$. 
Figure 5
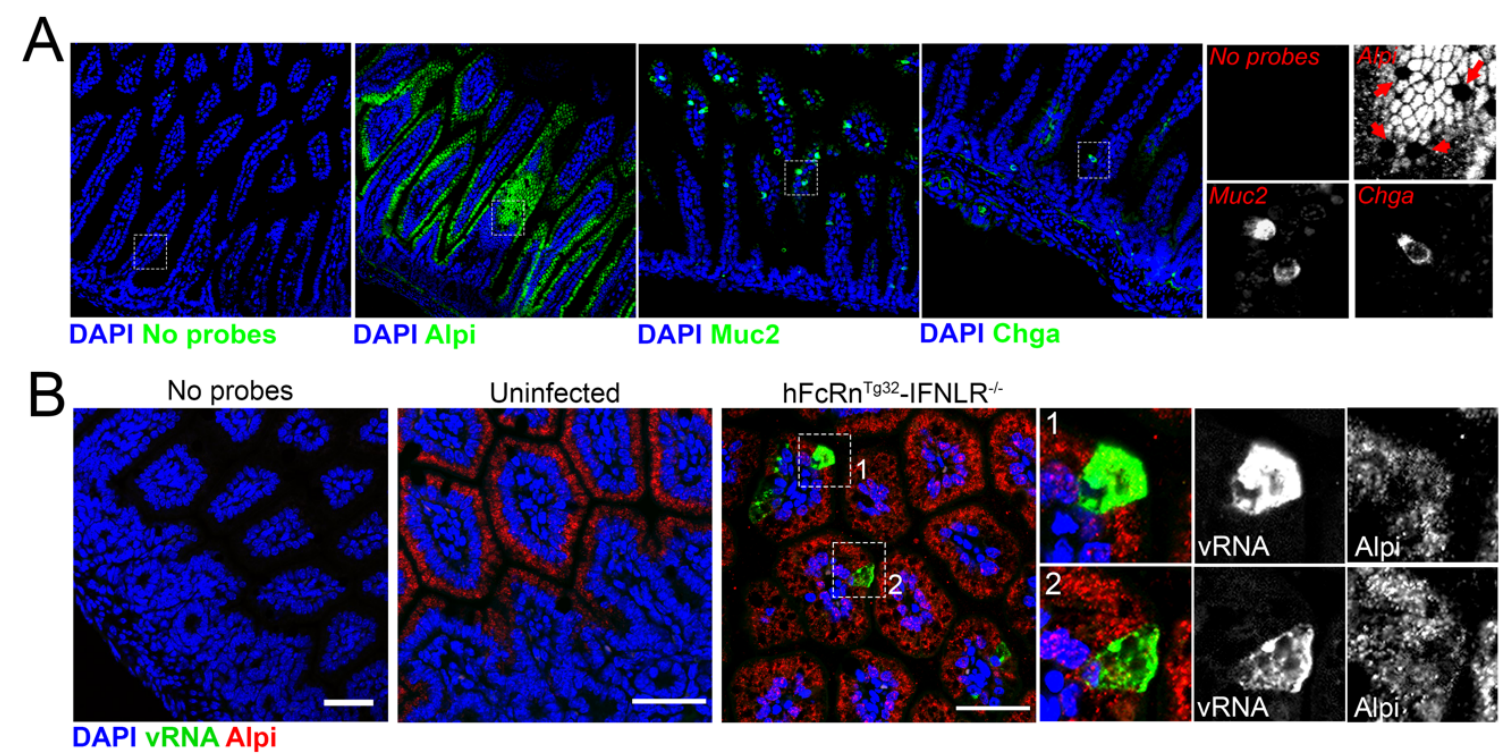

Uninfected $\mathrm{hFCRn}^{\mathrm{T} g 32}{ }^{-I F N L R}{ }^{-1-}$
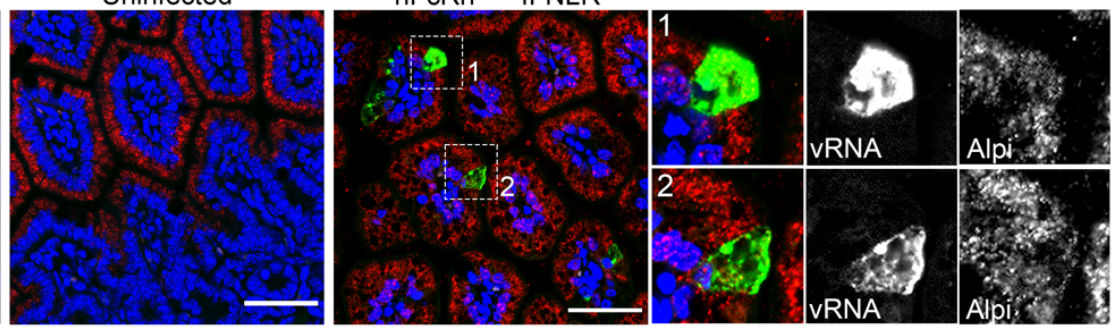

C
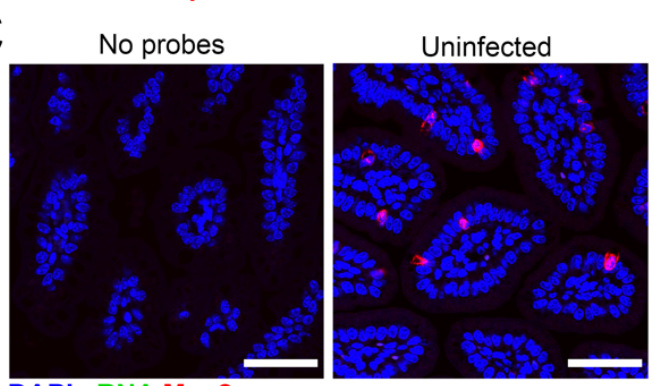

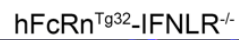

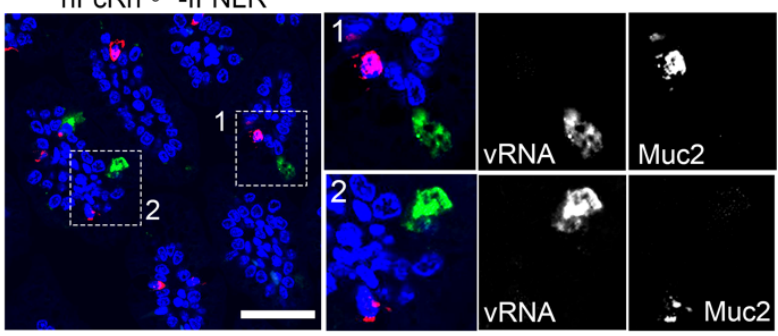

$\mathrm{D}$ DAPI vRNA Muc2

No probes

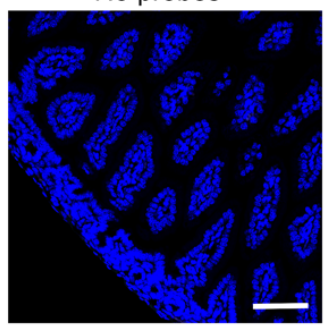

Uninfected

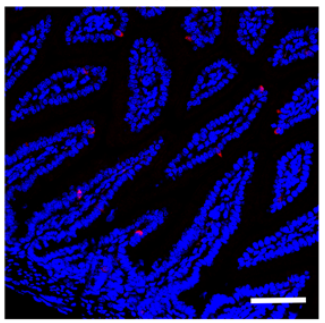

$\mathrm{hFCRn}^{\mathrm{Tg} 32}$-IFNLR ${ }^{-1-}$
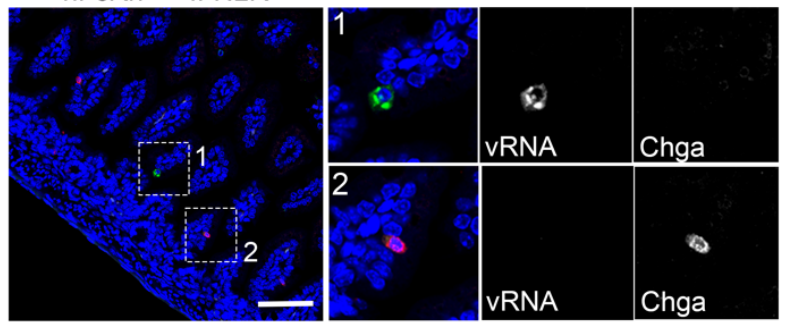

DAPI vRNA Chga

E

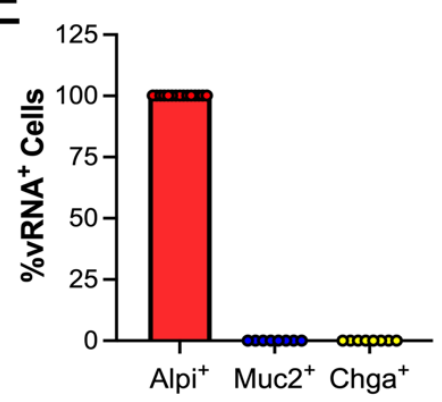

653 
Figure 5. In vivo replication of echoviruses is specific for enterocytes. (A) Hybridization chain reaction RNA-FISH (HCR) of uninfected small intestine sections using specific probes against Alpi, Muc2, or Chga (in green), as indicated at bottom. DAPI-stained nuclei are shown in blue. No probe containing control is shown at left. In all, white box is shown zoomed ( 6x) at right using the probes indicated in red. Red arrows in Alpi section denote goblet cells based on morphology that were not positive for Alpi, as expected. (B-D) 7-day old hFcRn ${ }^{\text {Tg32 }}$ IFNLR $^{-/-}$ neonatal mice were orally inoculated with $10^{6} \mathrm{PFU}$ of E5 and at $3 \mathrm{dpi}$, animals were sacrificed and the entire small intestine removed and Swiss rolled for subsequent histologic sectioning. Shown are representative images of ileum tissue using probes to E5 (green in all) and either Alpi (B), Muc2 (C), or Chga (D) (red in all). DAPI-stained nuclei are shown in blue. In all, white boxes denote zoomed areas shown at right, which include black and white images as indicated. Scale bars shown at bottom right $(50 \mu \mathrm{m})$. (E) Quantification of confocal images was performed using Fiji and was quantified as the total percentage of vRNA positive cells that colocalized with Alpi (in red), Muc2 (in blue), or Chga (in green). Note that there was no colocalization between vRNA and either Muc2 or Chga. 


\section{Supplemental Table 1}

Echovirus 5 HCR Probes

\begin{tabular}{|c|c|c|}
\hline $\begin{array}{l}\text { Probe } \\
\text { Pair }\end{array}$ & & \\
\hline B4P1 & $\begin{array}{l}\text { CCTCAACCTACCTCCAACAAGG } \\
\text { GCTCAGTAAACTTTCCCGGGTCT }\end{array}$ & $\begin{array}{l}\text { CATGGATTTGATCATAAGGTCCTT } \\
\text { CATTCTCACCATATTCGCTTC }\end{array}$ \\
\hline B4P2 & $\begin{array}{l}\text { CCTCAACCTACCTCCAACAAAGC } \\
\text { CCTGATGGAACTTAGATGCGTT }\end{array}$ & $\begin{array}{l}\text { CTTCAGGCACACACACCACCAGG } \\
\text { AGATTCTCACCATATTCGCTTC }\end{array}$ \\
\hline B4P3 & $\begin{array}{l}\text { CCTCAACCTACCTCCAACAAGCA } \\
\text { TTACTATGGTGGCACAATTGTT }\end{array}$ & $\begin{array}{l}\text { TGTCCATCGGTACGCTATTAATGT } \\
\text { AATTCTCACCATATTCGCTTC }\end{array}$ \\
\hline B4P4 & $\begin{array}{l}\text { CCTCAACCTACCTCCAACAATGC } \\
\text { TGCACCATCCTATAGTGGGTTT }\end{array}$ & $\begin{array}{l}\text { ATGTAGCCTGCTGCTGAGTATTCA } \\
\text { TATTCTCACCATATTCGCTTC }\end{array}$ \\
\hline B4P5 & $\begin{array}{l}\text { CCTCAACCTACCTCCAACAAGTT } \\
\text { ATGCTCAGACTTGGGCACGTCA }\end{array}$ & $\begin{array}{l}\text { TTGGCCAAAGGCTCCATATGTGTG } \\
\text { CATTCTCACCATATTCGCTTC }\end{array}$ \\
\hline B4P6 & $\begin{array}{l}\text { CCTCAACCTACCTCCAACAAGTG } \\
\text { ATCAGGTCATCGTGATTTCTTA }\end{array}$ & $\begin{array}{l}\text { CCAATGAGGGCTAGTGTGGCAGT } \\
\text { CAATTCTCACCATATTCGCTTC }\end{array}$ \\
\hline B4P7 & $\begin{array}{l}\text { CСTCAACCTACCTCCAACAAGAT } \\
\text { CTTCCAATTAGATTTGTTGCTA }\end{array}$ & $\begin{array}{l}\text { ACTGAGCTGTTAAGCTTTTCAGCT } \\
\text { AATTCTCACCATATTCGCTTC }\end{array}$ \\
\hline B4P8 & $\begin{array}{l}\text { CCTCAACCTACCTCCAACAACTC } \\
\text { CCTGTATAACGGTGGTCCCTGA }\end{array}$ & $\begin{array}{l}\text { TGTCTCTGGTGCAACACTAATTTT } \\
\text { GATTCTCACCATATTCGCTTC }\end{array}$ \\
\hline B4P9 & $\begin{array}{l}\text { CCTCAACCTACCTCCAACAATTA } \\
\text { GTGGGCGTGCCGCCCAGGTTTA }\end{array}$ & $\begin{array}{l}\text { GTGGGGAAGTTATACATGAGCATT } \\
\text { CATTCTCACCATATTCGCTTC }\end{array}$ \\
\hline B4P10 & $\begin{array}{l}\text { CCTCAACCTACCTCCAACAAAGC } \\
\text { GCTTCAAGACCCTCAGTACCGT }\end{array}$ & $\begin{array}{l}\text { TGGGTAACCGGCGCTCGTTGTTA } \\
\text { GATATTCTCACCATATTCGCTTC }\end{array}$ \\
\hline B4 & $\begin{array}{l}\text { CCTCAACCTACCTCCAACAATGC } \\
\text { ACAAGTAGTCAATGTAGTTAGT }\end{array}$ & $\begin{array}{l}\text { GCTTGTCTCTGTACAGGTGATGG } \\
\text { GAATTCTCACCATATTCGCTTC }\end{array}$ \\
\hline B4 & $\begin{array}{l}\text { CCTCAACCTACCTCCAACAATTT } \\
\text { CACGAATGTTGATCTCCCACCT }\end{array}$ & $\begin{array}{l}\text { TCTCACACTTTCTACGTAGTTGCA } \\
\text { CATTCTCACCATATTCGCTTC }\end{array}$ \\
\hline
\end{tabular}




\section{Supplemental Table 2}

Muc2 HCR Probes

\begin{tabular}{|c|c|c|}
\hline $\begin{array}{l}\text { Probe } \\
\text { Pair }\end{array}$ & & \\
\hline B1P1 & $\begin{array}{l}\text { GAGGAGGGCAGCAAACGGAAGA } \\
\text { GAGGCCGGCCCGAGAGTAGACCT }\end{array}$ & $\begin{array}{l}\text { AGTGCATCTTCCCGGTTCCACATG } \\
\text { ATAGAAGAGTCTTCCTTTACG }\end{array}$ \\
\hline B1P2 & $\begin{array}{l}\text { GAGGAGGGCAGCAAACGGAACG } \\
\text { CAGGGCGAGCTGCTCTCCAGGTA }\end{array}$ & $\begin{array}{l}\text { TAACCTCCAGATGTGAGCATGTGT } \\
\text { CTAGAAGAGTCTTCCTTTACG }\end{array}$ \\
\hline B1P3 & $\begin{array}{l}\text { GAGGAGGGCAGCAAACGGAAAGT } \\
\text { CTTCAGGCAGGTCTGCTTGTCT }\end{array}$ & $\begin{array}{l}\text { CTTCTTGTCGTCAGTCAACAGCAC } \\
\text { GTAGAAGAGTCTTCCTTTACG }\end{array}$ \\
\hline B1P4 & $\begin{array}{l}\text { GAGGAGGGCAGCAAACGGAAGG } \\
\text { AACACCAGTGCTCAGCGTAGTTG }\end{array}$ & $\begin{array}{l}\text { AAAGGGCGTCTCTGACCTCTTCAG } \\
\text { GTAGAAGAGTCTTCCTTTACG }\end{array}$ \\
\hline B1P5 & $\begin{array}{l}\text { GAGGAGGGCAGCAAACGGAAATA } \\
\text { CACTCAGTATGGTAATAGCCAG }\end{array}$ & $\begin{array}{l}\text { AGTCCATCGGGACACACACAGCC } \\
\text { ACTAGAAGAGTCTTCCTTTACG }\end{array}$ \\
\hline B1P6 & $\begin{array}{l}\text { GAGGAGGGCAGCAAACGGAAAG } \\
\text { GTACTGACCCACTTCCCGTGTGA }\end{array}$ & $\begin{array}{l}\text { ATGATGCCGGAGCTGGCTTCCAC } \\
\text { CATAGAAGAGTCTTCCTTTACG }\end{array}$ \\
\hline B1P7 & $\begin{array}{l}\text { GAGGAGGGCAGCAAACGGAAGAA } \\
\text { CTCCCAGTAGCAGAAGATACCA }\end{array}$ & $\begin{array}{l}\text { TTGCCCCACTGTTCCATTGGGGC } \\
\text { CGTAGAAGAGTCTTCCTTTACG }\end{array}$ \\
\hline B1P8 & $\begin{array}{l}\text { GAGGAGGGCAGCAAACGGAATTA } \\
\text { ATGGGGTGGTTGGTGAAGTAGT }\end{array}$ & $\begin{array}{l}\text { TTGTTGGTGAGGTGGTTGGTGAG } \\
\text { GTTAGAAGAGTCTTCCTTTACG }\end{array}$ \\
\hline B1P9 & $\begin{array}{l}\text { GAGGAGGGCAGCAAACGGAAAGA } \\
\text { TGGTTGGTGAGGTGGTTGAAGG }\end{array}$ & $\begin{array}{l}\text { TAGGAGAGATGGTTGATGTTGTTA } \\
\text { TTAGAAGAGTCTTCCTTTACG }\end{array}$ \\
\hline B1 & $\begin{array}{l}\text { GAGGAGGGCAGCAAACGGAAGTG } \\
\text { AACTGGTTGATGGAGTGGTAGG }\end{array}$ & $\begin{array}{l}\text { TTGGTGAGGTGGTTGATGGGGTG } \\
\text { GTTAGAAGAGTCTTCCTTTACG }\end{array}$ \\
\hline B1 & $\begin{array}{l}\text { GAGGAGGGCAGCAAACGGAAAG } \\
\text { GCACGAAGGCGTGGCACTGGGA }\end{array}$ & $\begin{array}{l}\text { CAGGCAAGCTTCATAGTAGTGCTT } \\
\text { GTAGAAGAGTCTTCCTTTACG }\end{array}$ \\
\hline B & $\begin{array}{l}\text { GAGGAGGGCAGCAAACGGAATAC } \\
\text { AGGGCACATGGGTACAGGAGAT }\end{array}$ & $\begin{array}{l}\text { GCTCAAAGCCAGAGCTGCAGGAG } \\
\text { ATTAGAAGAGTCTTCCTTTACG }\end{array}$ \\
\hline
\end{tabular}




\section{Supplemental Table 3}

Chga HCR Probes

\begin{tabular}{|c|c|c|}
\hline $\begin{array}{l}\text { Probe } \\
\text { Pair }\end{array}$ & & \\
\hline B1P1 & $\begin{array}{l}\text { GAGGAGGGCAGCAAACGGAAGCA } \\
\text { ATGCTATGCCGGCTTTTATATA }\end{array}$ & $\begin{array}{l}\text { ATGGTGGCGGTGGCGGCGGCAG } \\
\text { CAGTAGAAGAGTCTTCCTTTACG }\end{array}$ \\
\hline B1P2 & $\begin{array}{l}\text { GAGGAGGGCAGCAAACGGAAGAA } \\
\text { AGAGTGGACGAGCTGCTGCAGG }\end{array}$ & $\begin{array}{l}\text { GGAGCGCATAGCGAGCCGGACG } \\
\text { GTGTAGAAGAGTCTTCCTTTACG }\end{array}$ \\
\hline B1P3 & $\begin{array}{l}\text { GAGGAGGGCAGCAAACGGAAGTC } \\
\text { GGAGATGACTTCCAGGACGCAC }\end{array}$ & $\begin{array}{l}\text { AGGCATGGGGCTGGGTTTGGACA } \\
\text { GCTAGAAGAGTCTTCCTTTACG }\end{array}$ \\
\hline B1P4 & $\begin{array}{l}\text { GAGGAGGGCAGCAAACGGAAGCT } \\
\text { GCTGCTGCTGCTGCTGCTGCT }\end{array}$ & $\begin{array}{l}\text { TCAAAGCTGCTGTGTTGCTGCTCC } \\
\text { TTAGAAGAGTCTTCCTTTACG }\end{array}$ \\
\hline B1P5 & $\begin{array}{l}\text { GAGGAGGGCAGCAAACGGAATCT } \\
\text { TGGTTAGGCTCTGGAAAGGCCT }\end{array}$ & $\begin{array}{l}\text { GACTCACTGTCTCCCATCATGGG } \\
\text { GGTAGAAGAGTCTTCCTTTACG }\end{array}$ \\
\hline B1P6 & $\begin{array}{l}\text { GAGGAGGGCAGCAAACGGAACCT } \\
\text { TCTCTCTAGCCACAGCCTCCTC }\end{array}$ & $\begin{array}{l}\text { CTGCAGTGGGGACTTCTTCAGGC } \\
\text { CCTAGAAGAGTCTTCCTTTACG }\end{array}$ \\
\hline B1P7 & $\begin{array}{l}\text { GAGGAGGGCAGCAAACGGAAGGT } \\
\text { CCCTACCATGGCCTCTTCCCCA }\end{array}$ & $\begin{array}{l}\text { CCCGCCTTGGGGGAAGAGACCTT } \\
\text { GGTAGAAGAGTCTTCCTTTACG }\end{array}$ \\
\hline B1P8 & $\begin{array}{l}\text { GAGGAGGGCAGCAAACGGAACG } \\
\text { GGTCCGGAAGGAGAGCTTCATGG }\end{array}$ & $\begin{array}{l}\text { GGCCCAGGATCTCTGAAGCCATA } \\
\text { GGTGAAGAGTCTTCCTTTACG }\end{array}$ \\
\hline B1 & $\begin{array}{l}\text { GAGGAGGGCAGCAAACGGAAGCT } \\
\text { CTCTAGCTCCTGGTCCTCTGCT }\end{array}$ & $\begin{array}{l}\text { CTCCAGCTCTGCCTCGATGGCTG } \\
\text { ACTAGAAGAGTCTTCCTTTACG }\end{array}$ \\
\hline B & $\begin{array}{l}\text { GAGGAGGGCAGCAAACGGAAAAG } \\
\text { TGTCCAGGGCAGGGGCTGAGAA }\end{array}$ & $\begin{array}{l}\text { GTGCTGACATTCAGGGCTGCCCT } \\
\text { GCTAGAAGAGTCTTCCTTTACG }\end{array}$ \\
\hline
\end{tabular}




\section{Supplemental Figure 1}
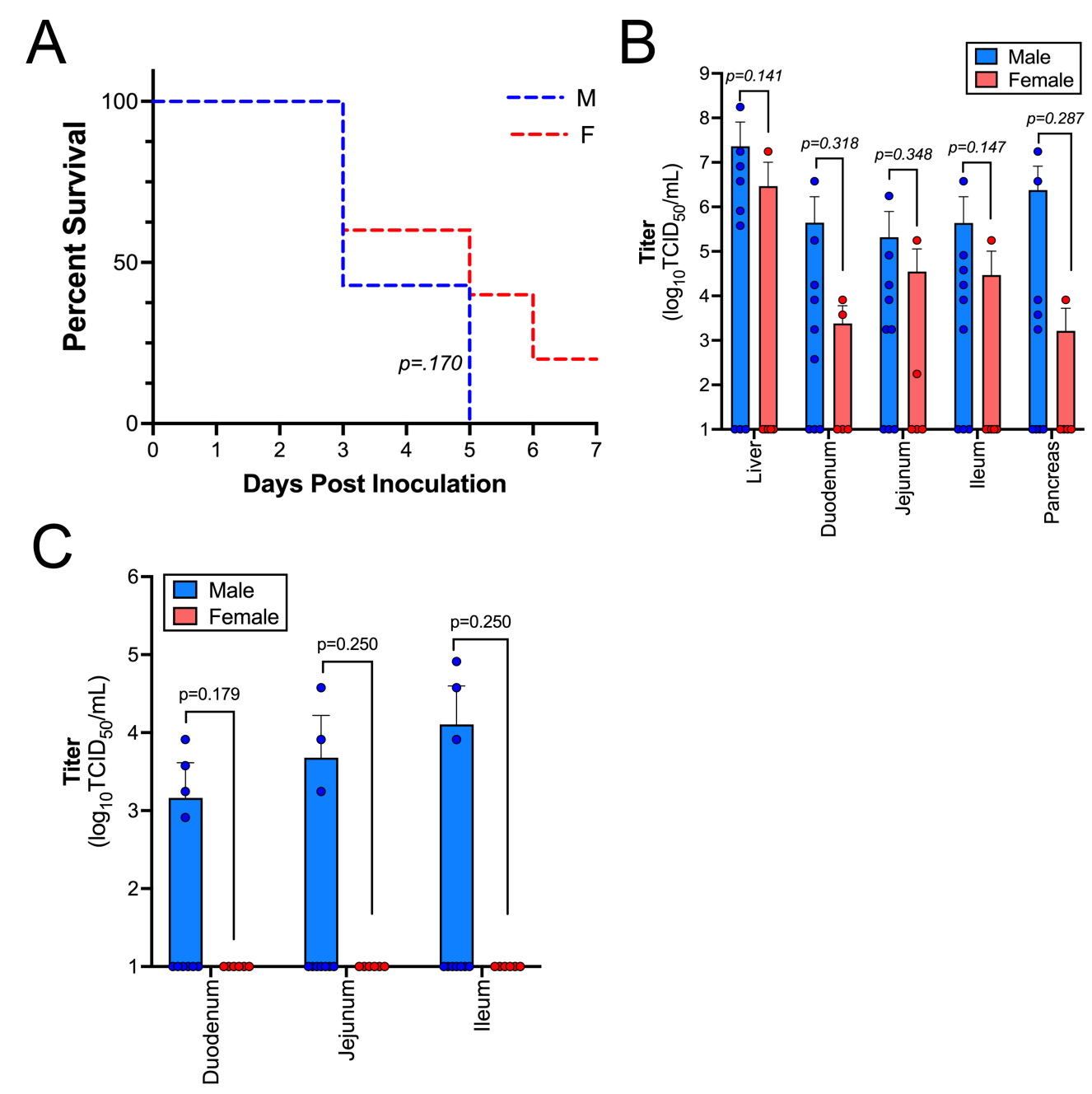

Supplemental Figure 1. 7-day old pups were orally inoculated with $10^{6}$ PFU of E5. (A) Survival curve of $\mathrm{hFCRn}^{\mathrm{Tg} 32}$-IFNAR ${ }^{-/-}$animals broken down by sex. A log-rank test was used to analyze the statistical difference of the survival rate. (B) Viral titers of $\mathrm{hFcRn}^{\mathrm{Tg} 32}$-IFNAR ${ }^{-1-}$ animals at $3 \mathrm{dpi}$ broken down by sex. (C) Viral titers of hFcRn ${ }^{T 932}$ IFNLR $^{-1-}$ animals at 7 dpi broken down by sex. Significance was determined by Mann-Whitney $U$ test ( $p$ values shown). Each symbol represents an individual animal. 


\section{Supplemental Figure 2}

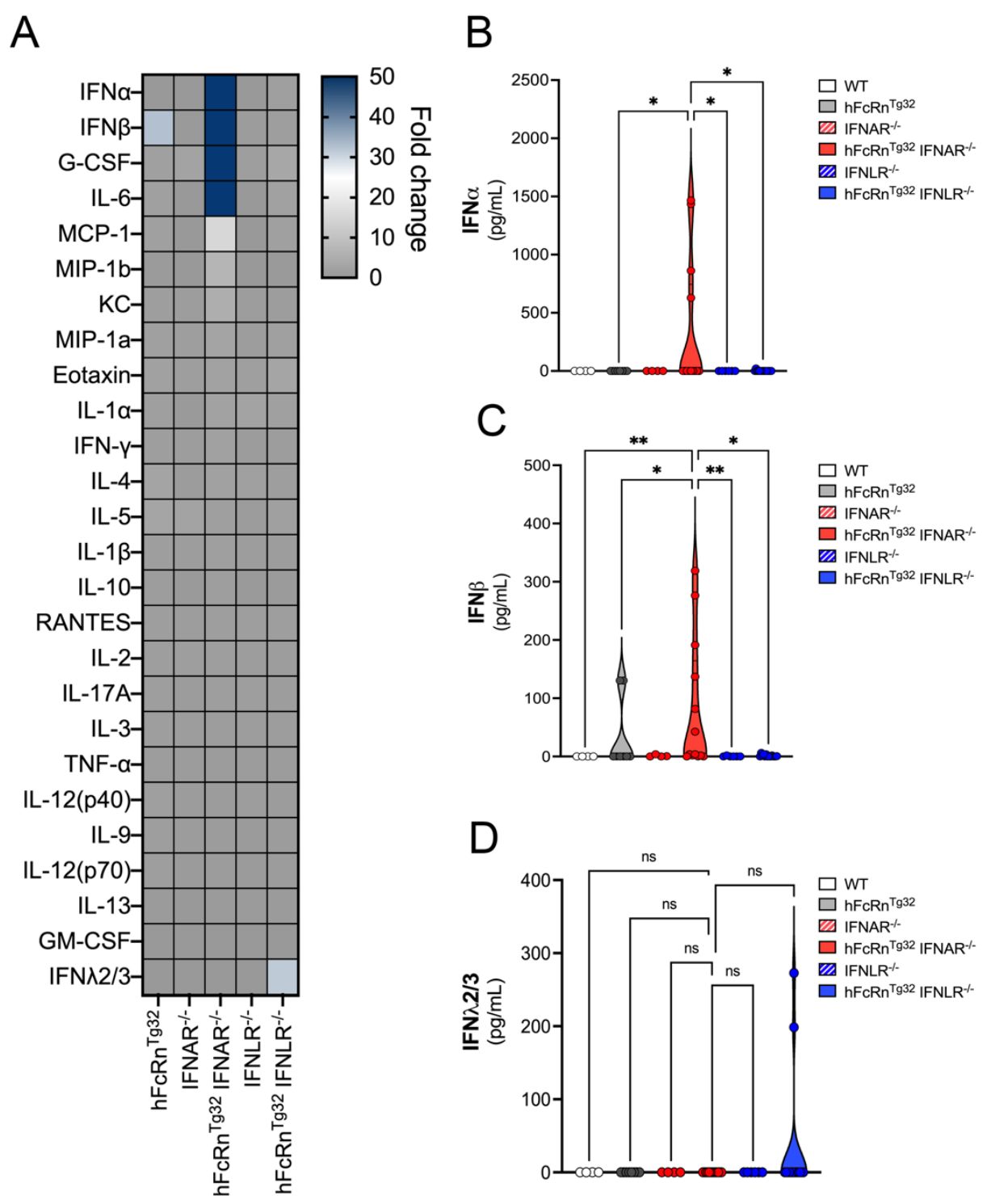

Supplemental Figure 2. Neonatal mice were inoculated by the oral route with $10^{6} \mathrm{PFU}$ of E5 and sacrificed 3 dpi. Luminex-based multianalyte profiling of 26 cytokines was then performed from whole blood. (A) Heatmap demonstrating the induction (shown as fold-change from uninfected control) in E5-infected mice of the indicated genotype. Blue denotes significantly increased cytokines in comparison to untreated. Grey or white denote little to no changes (scale at top right). The IFNs are shown to the right as $\mathrm{pg} / \mathrm{mL}$ IFNa (B), IFN $\beta$ (C), and IFN $\lambda 2 / 3$ (D). Data are shown as mean \pm standard deviation and individual animals (points). Data are shown with significance determined with a Kruskal-Wallis test with a Dunn's test for multiple comparisons $\left({ }^{*} p<0.05\right.$, ${ }^{* *} p<0.005$, ns-nt significant). Each symbol represents an individual animal. 


\section{Supplemental Figure 3}

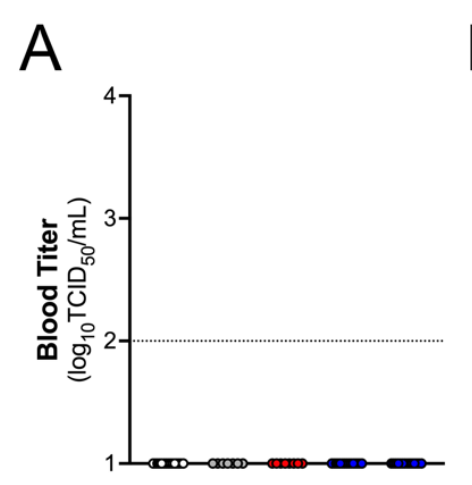

B
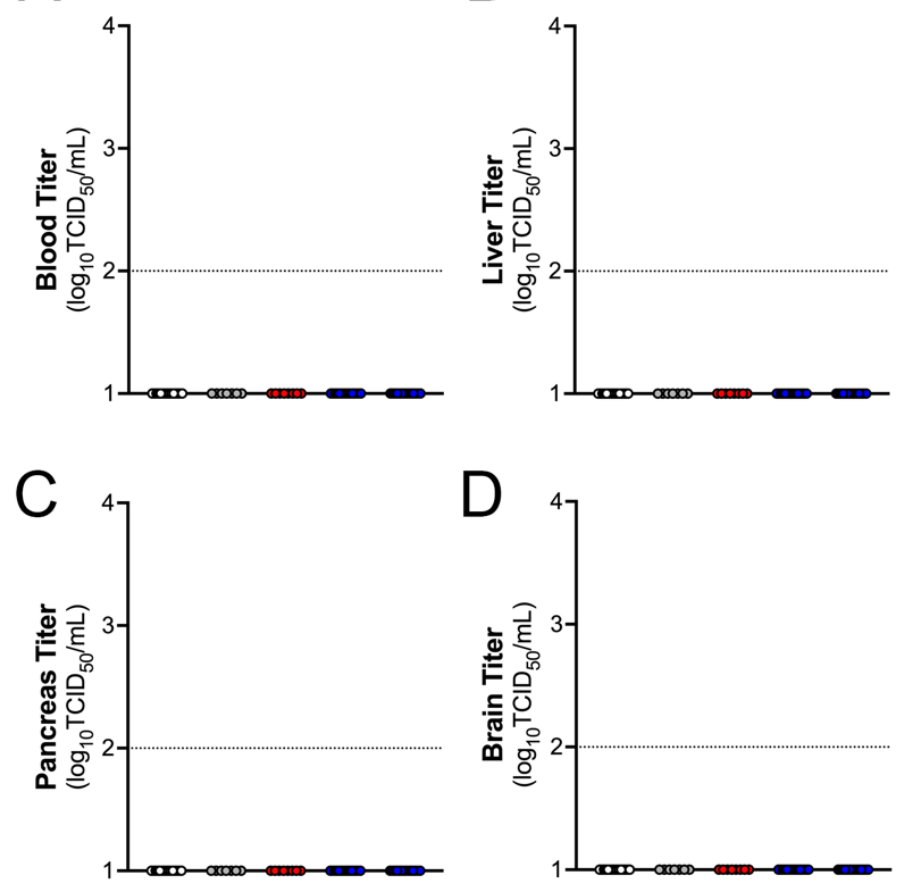

$\square$ WT

$\square \mathrm{hFcRn}{ }^{\top 932}$ 四 IFNAR ${ }^{-1}$

$\mathbb{Z}$ IFNLR $^{-1-}$

$\square \mathrm{hFcRn}{ }^{T 932}$ IFNLR ${ }^{-1}$

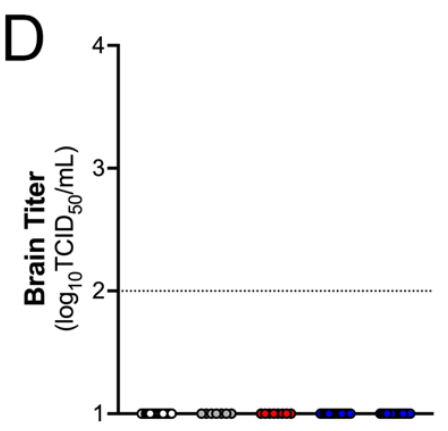

$\square$ WT

$\square \mathrm{hFcRn}{ }^{\mathrm{Tg}} 32$

$\mathbb{Z}$ IFNAR $^{-1-}$

$\mathbb{Z} \mathrm{IFNLR}^{-1-}$

$\square \mathrm{hFCRn}{ }^{\top 932}$ IFNLR $^{-1-}$

Supplemental Figure 3. 7-day old pups were orally inoculated with $10^{6}$ PFU of E5. At 7 dpi, animals were sacrificed to measure viral replication in tissues. Viral titers are shown as $\log _{10}$ TCID50/mL in the blood (A), liver (B), pancreas (C), and brain (D). Data are shown as mean \pm standard deviation and individual animals (points). Data are shown with significance determined with a Kruskal-Wallis test with a Dunn's test for multiple comparisons $\left({ }^{*} p<0.05,{ }^{* *} p<0.005\right)$. Each symbol represents an individual animal. 


\section{Supplemental Figure 4}
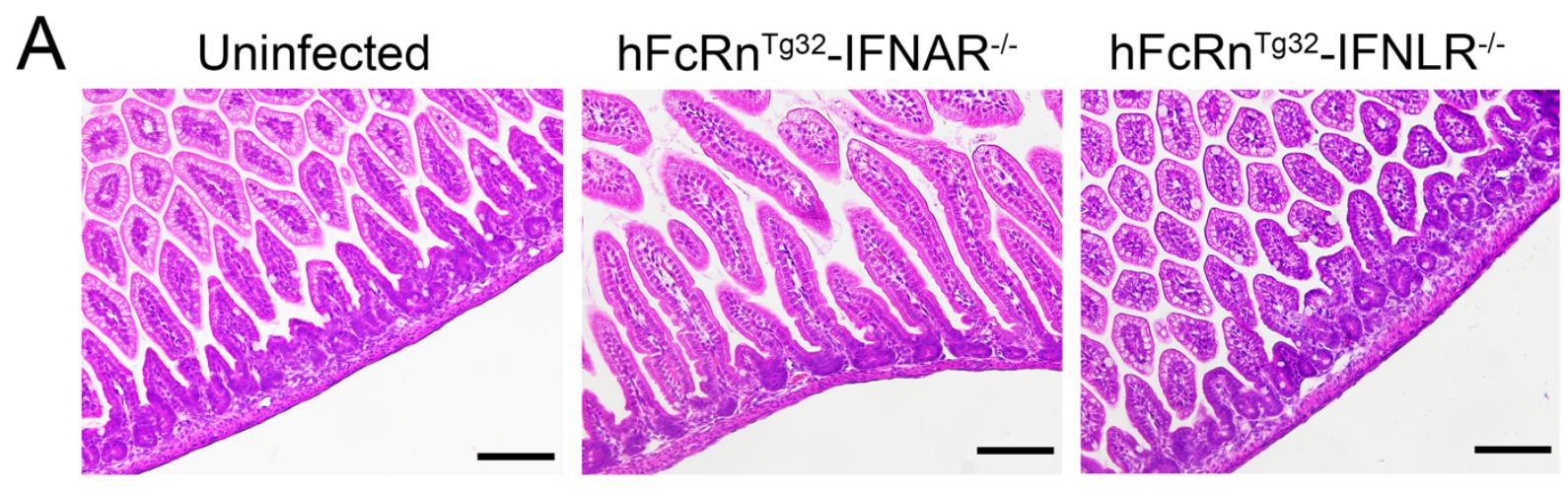

B
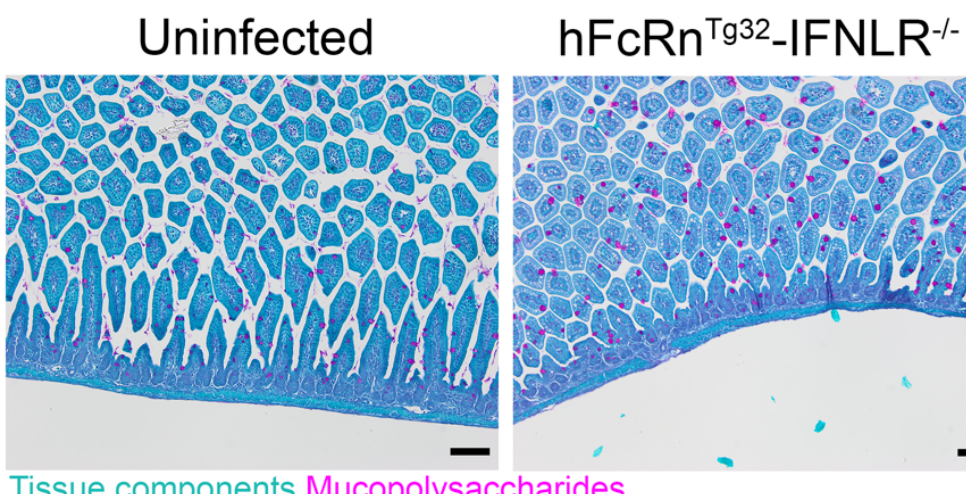

Tissue components Mucopolysaccharides

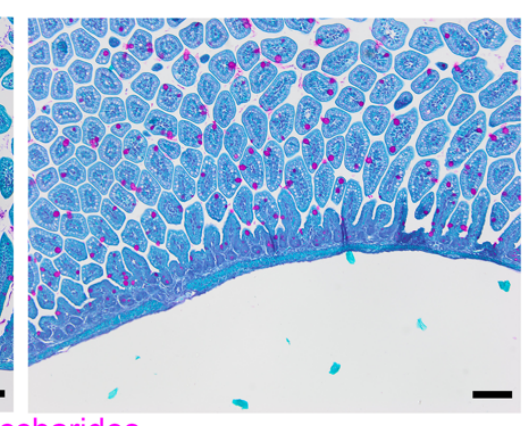

Supplemental Figure 4. 7-day old pups were orally inoculated with $10^{6}$ PFU of E5. At 3dpi, animals were sacrificed and intestines were collected for histology. (A) Hematoxylin and eosin staining of representative intestinal sections from uninfected, $\mathrm{hFcRn}{ }^{\mathrm{Tg} 32}$-IFNAR ${ }^{-/}$, or $\mathrm{hFcRn}^{\mathrm{Tg} 32}$ IFNLR ${ }^{-/-}$animals. (B) Periodic Acid Schiff staining of representative intestinal sections uninfected or $\mathrm{hFCRn}^{\text {Tg32 }}{ }_{\text {IFNLR }}{ }^{-/}$animals to identify goblet cells. Scale bars at bottom right $(100 \mathrm{~mm})$. 


\section{Supplemental Figure 5}

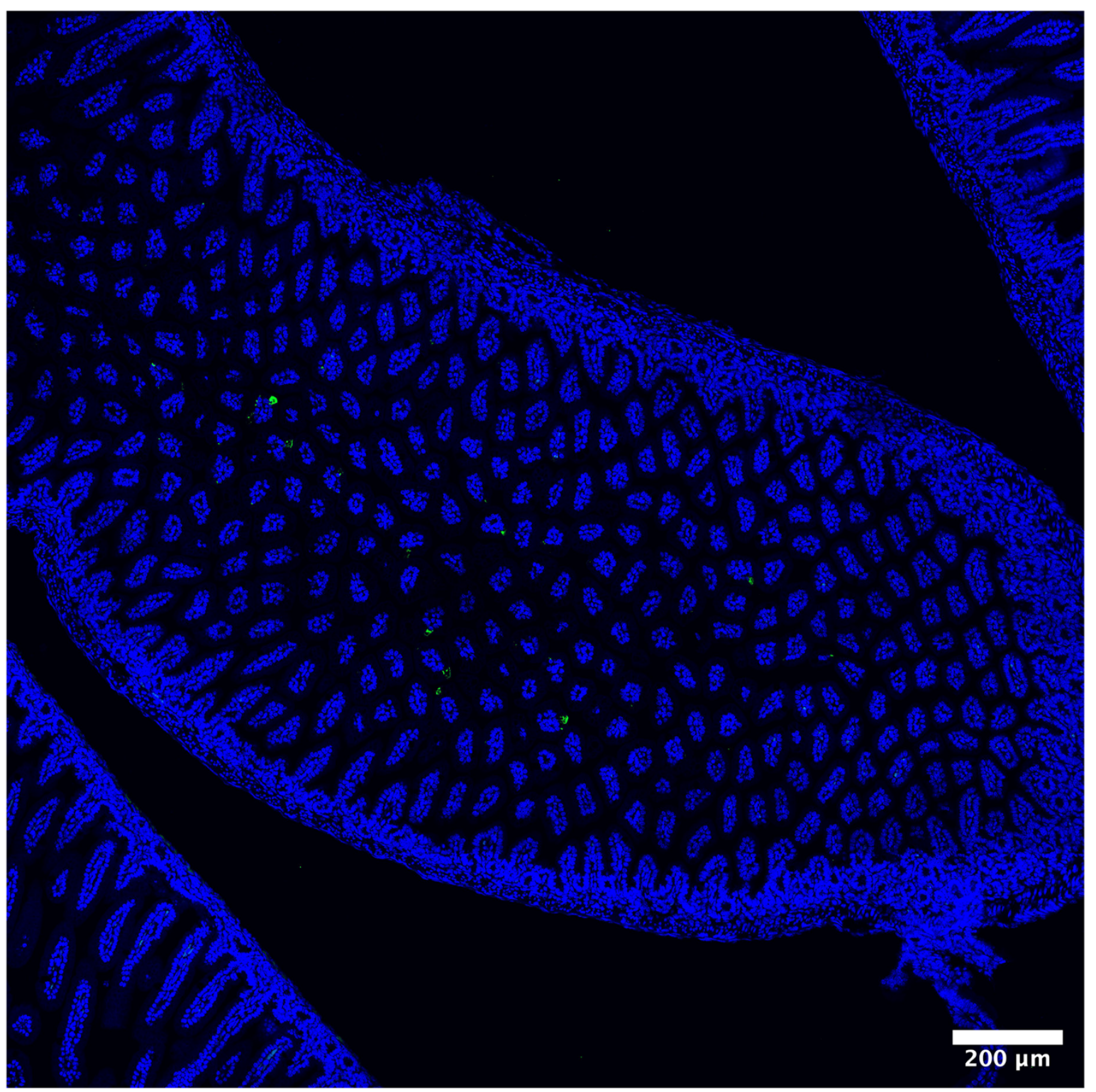

Supplemental Figure 5. Representative tile scan of an ileum from a hFcRn ${ }^{T g 32}$ IFNLR ${ }^{-/-}$pup with vRNA shown in green and DAPI in blue. Tile scan was done at a 20x magnification with an area of 6 by 6 tiles combined for a total of 36 individual images that were stitched together. The total area of view is $4 \mathrm{~mm}^{2}$ per image. 